NBSIR $73-343$

\title{
CALIBRATION OF IMPULSE NOISE GENERATORS
}

Gerome R. Reeve

Electromagnetics Division

Institute for Basic Standards

National Bureau of Standards

Boulder, Colorado 80302

October 1973

Final Report

U.S. Army Contract 67-95896

Prepared for

U.S. Army Electronics Command AMSEL-NL-C

Fort Monmouth, New Jersey 

NBSIR $73-343$

\section{CALIBRATION OF IMPULSE NOISE GENERATORS}

Gerome R. Reeve

Electromagnetics Division

Institute for Basic Standards

National Bureau of Standards

Boulder, Colorado 80302

October 1973

Final Report

U.S. Army Contract 67-95896

Prepared for

U.S. Army Electronics Command

AMSEL-NL-C

Fort Monmouth, New Jersey

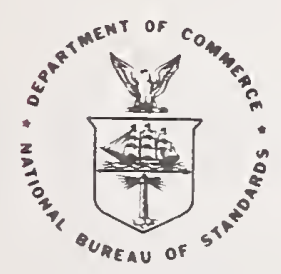

U.S. DEPARTMENT OF COMMERCE, Frederick B. Dent, Secretary NATIONAL BUREAU OF STANDARDS. Richard W Roberts. Director 



\section{CONTENTS}

$\underline{\text { Page }}$

I. HISTORY OF PROJECT $\ldots \ldots \ldots \ldots$

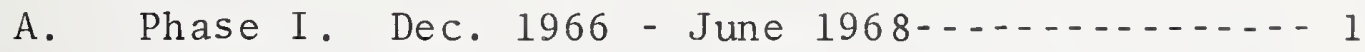

B. Phase II. Jan.1970 - June 1972.......... I

II . TECHNICAL REPORT $\ldots \ldots \ldots$

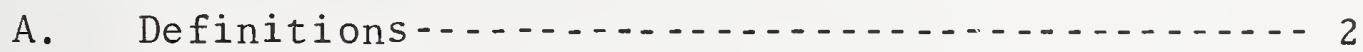

B. Possible Methods of Calibration........... 3

1. Standard Impulse Generator Method........ 3

2. Measured Baseband Impulse Method-...... 5

3. Measured Spectral Intensity Method...... 5

C. Accomplishments of Phase I............ 8

D. Accomplishments of Phase II ............... 9

1. Continuous Frequency Coverage.......... 9

2. $30 \mathrm{MHz}$ and $1 \mathrm{GHz}$ Radiometers.......... 13

3. $1 \mathrm{GHz}$ Thermal Noise Sources............ 21

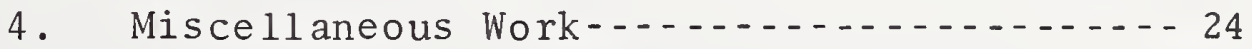

E. Observations on Impulse Generators-...-.-.-25

1. Mechanical Switches-................. 25

2. Mercury Wetted Switches -............ 26

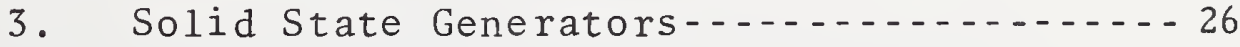

III. PROPOSED COURSE FOR FUTURE WORK - ............. 28

A. Planning Considerations $\ldots \ldots \ldots \ldots$

B. A Newly Proposed System for Calibrating Impulse Generators -........................ 31 
C. Proposed Standard Impulse Spectra Generators-- 33

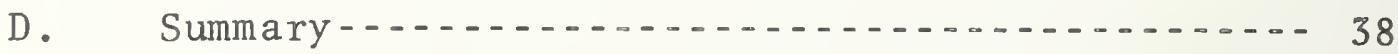

IV. ACKNOWLEDGMENTS - . $\ldots \ldots \ldots \ldots$

V. REFERENCES - ........ 40

\section{LIST OF FIGURES}

Figure 1. SDC Radiometer Block Diagram, $30 \mathrm{MHz} . \ldots . \ldots . . .41$

Figure 2. SDC Radiometer Block Diagram, $1 \mathrm{GHz} . \ldots . . . .-42$

Figure 3. Typical Swept Response with Small Frequency Increments (Bandwidth Determination, Receiver

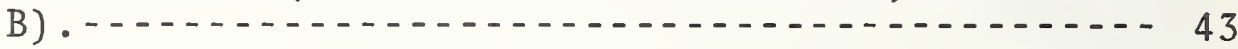

Figure 4. Bandwidth vs. Frequency, 0.015-2.0 MHz,

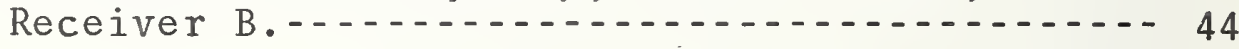

Figure 5. Bandwidth vs. Frequency, 1.5-100 MHz,

Receiver B.

Figure 6. Bandwidth vs. Frequency, 1.5-1000 MHz,

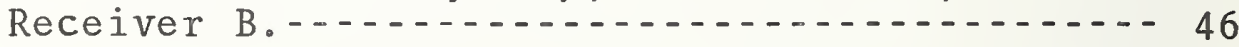

Figure 7. Gain vs. Frequency, 0.015-2.0 MHz, Receiver B. 47

Figure 8. Gain vs. Frequency, 1.5-100 MHz, Receiver B.-- 48

Figure 9. Gain vs. Frequency, 1.5-1000 MHz, Receiver B.- 49

Figure 10. Null Sensitivity of Radiometer at $30 \mathrm{MHz}$, $1 \mathrm{~dB}$ change at $40 \mathrm{~dB}$ above $1 \mu \mathrm{V} / \mathrm{MHz}, 1 \mathrm{kHz}$ Repetition Rate, (10 minor vertical div. =

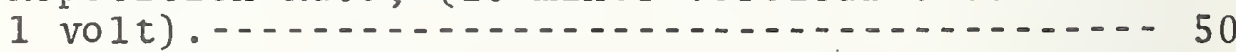

Figure 11. Null Sensitivity of Radiometer at $1 \mathrm{GHz}, 1 \mathrm{~dB}$ change at $40 \mathrm{~dB}$ above $1 \mu \mathrm{V} / \mathrm{MHz}, 1 \mathrm{kHz}$ Repetition Rate, (10 minor vertical div. $=1$ volt).-5I

Figure 12. Null Sensitivity of Radiometer at $30 \mathrm{MHz}, 1 \mathrm{~dB}$ change at $30 \mathrm{~dB}$ above $1 \mu \mathrm{V} / \mathrm{MHz}, 100 \mathrm{~Hz}$ Repetition Rate, ( 10 minor vertical div. $=0.2$ volts) 52 


\section{LIST OF FIGURES (Continued)}

Figure 13. Null Sensitivity of Radiometer at $1 \mathrm{GHz}, 1 \mathrm{~dB}$ change at $40 \mathrm{~dB}$ above $1 \mu \mathrm{V} / \mathrm{MHz}, 100 \mathrm{~Hz}$ Repetition Rate, (10 minor vertical div. $=0.2$ volts) 53

Figure 14. Theoretical Useful Operating Range of Radiometer............................ 54

Figure 15. Useful Range of Operation, Measured on Breadboard Radiometer at $30 \mathrm{MHz}$........... 55

Figure 16. Sum and Difference Correlation Radiometer $30 \mathrm{MHz}$ and $1 \mathrm{GHz}$ Phase II.................. 56

Figure 17. I GHz Hot and Cold Thermal Noise Sources-..- 57

Figure 18. Interior of $1 \mathrm{GHz}$ Hot Thermal Noise Source--- 58

Figure 19. Interior of $1 \mathrm{GHz}$ Cold Thermal Noise Source-- 59

Figure 20. Impulse Produced by Avalanche Transistor Comb

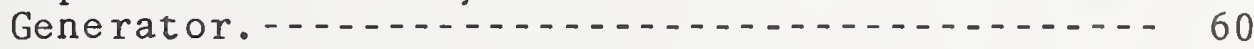

Figure 21. Fourier Transform of Impulse of Figure 20.--- 61

Figure 22. Schematic of Avalanche Transistor Impulse

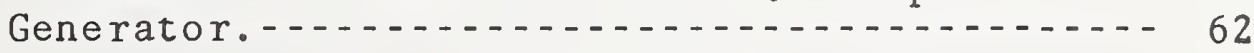

Figure 23. Output of Developmental Solid State Impulse Generator, Wright Patterson AFB......... 63

Figure 24. Proposed Automated Impulse Calibration System - Block Diagram.-.................... 64

Figure 25. Plot of : Phase Corrections vs. $\tau, 3-5 \mathrm{rf}$

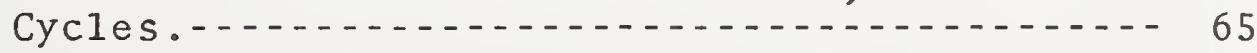

Figure 26. Plot of $\%$ Phase Corrections vs. $\tau, 14-16 \mathrm{rf}$

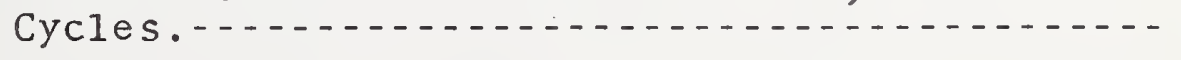

\section{LIST OF TABLES}

Table I. Difference in Impulse Response at Band Overlap Frequencies, Receiver A. .............. 67

Table II. Performance of $1 \mathrm{GHz}$ Waveguide Beyond Cutoff

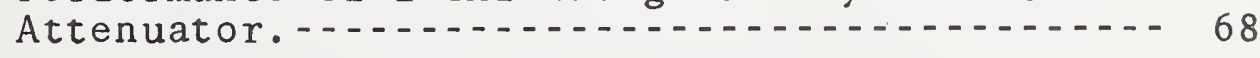

Table III. Percent Phase Correction for Synchronous

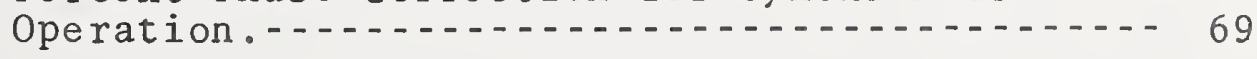

Table IV. Parameters of Calibration Signals-........- 71 


\section{CALIBRATION OF IMPULSE NOISE GENERATORS}

This report covers work performed by the Electromagnetics Division, Institute for Basic Standards, National Bureau of Standards, on a Signal Corps contract to develop a calibration system for impulse noise generators. Various technical approaches are discussed with their respective problems. A prototype system which was constructed is presented along with some measurements of its capability. Finally another approach is suggested utilizing newer techniques and instrumentation which should come closer to achieving the desired level of performance.

Key words: Impulse; impulse noise; impulse noise generator, impulse generator calibration. 


\section{I . HISTORY OF PROJECT}

\section{A. Phase I. Dec. 1966 - June 1968}

In September 1966 the U.S. Army Electronics Command, Ft. Monmouth, N.J. (USAECOM) issued a technical requirement (SCL9035 ) for a calibration standard for impulse noise generators. The Engineering Division of the Radio Standards Laboratory of the National Bureau of Standards responded with a proposal which resulted in the issuing of a contract at the end of December 1966 for services to "... consist of developing and setting up a National Facility for Calibration of the Spectral Intensity of Impulse Generators in accordance with Technical Requirement SCL-9035 ..." This contract was funded in the amount of $\$ 100,000$ and was to run through June of 1968 .

With the expiration of the allotted time and funds in June 1968, work on the project halted and a report (NBS Report 9743 - - Standards and Measurement of Impulse Spectral Intensity) was issued covering the accomplishments and outlining what work yet needed to be done.

B. Phase II. Jan. 1970 - June 1972

In January 1970 , the USAECOM continued the funding of the original project in an amount of $\$ 108,400$ and extended the time 
period to run through September 1971. By February 1971, the funds were expended while the technical objectives were not reached. In July 1971 the funding was supplemented with $\$ 25,000$ from USAECOM and $\$ 25,000$ from the Electromagnetics Division of the National Bureau of Standards. Because of other commitments work on this effort did not resume until October 1971 and continued until June 1972. Although the objective of creating a "calibration service" was not reached, progress was made toward this goal as described in the following section.

\section{TECHNICAL REPORT}

\section{A. Definitions}

The problem of defining the quantity of impulse spectral intensity has been discussed in the previous reports covering phase I of this project $[1,2]$. The following is only a brief summary and the reader is referred to the references cited for a fuller discussion.

Mathematically, the impulse spectral intensity, $V(f)$, has been considered to be proportional to the absolute value of the Fourier transform of one of the following:

(1) a single pulse;

(2) a finite train of identical pulses;

(3) an infinite train of identical pulses. 
Number (1) is usually chosen as the representation since the results of (2) depend on the length of the train of pulses and (3) has some mathematical difficulties in obtaining a rigorous solution. A more serious problem for engineers is the constant of proportionality mentioned above. Depending upon the circuit model chosen and the mathematical technique used it is possible to justify 1,2 , or $\sqrt{2}$. This has caused no end of misunderstanding and confusion in the marketplace. Since the resolution of these questions must involve a common understanding and a consensus acceptable to the engineering community, it more logically falls within the purview of the cognizant committee of professional engineering societies.

\section{B. Possible Methods of Calibration}

There are several methods which can and have been used to calibrate impulse generators each having particular advantages and disadvantages. These are listed below; while the list is not exhaustive, it should help to put the work of this project into better perspective.

1. Standard Impulse Generator Method.

(a) Standard Base Band Impulse Generator. Theoretically it is possible to build a device to generate an impulsive type of signal* whose characteristics

*In this report the word impulse or impulse signal is used to refer to the type of signal which is produced by commercial impulse generators. Typically it consists of a train of narrow ( $<1$ nanosecond) pulses with a repetition period between $10^{-1}$ and $10^{-6}$ seconds. 
are completely calculable from the physical constants of the generator. Such a generator could consist of a section of ideal transmission line charged to a known dc voltage, and an ideal switch. From the line and switch parameters, and the voltage, the shape of impulse can be calculated. By means of the Fourier transform, the spectral intensity as a function of frequency may be calculated. Using this known generator as a standard, unknown generators could be compared to it using an acceptable comparator receiver. In practice, however, it is extremely difficult if not impossible to build a generator whose output can be accurately calculated from the physical constants of the generator. At higher frequencies, >0.1 GHz, parasitic reactances and losses cause perturbations in the output spectrum which become progressively worse as the frequency increases.

(b) Standard Pulsed RF Generator. Instead of constructing a base band impulse generator it is possible to pulse modulate a CW rf signal to create a flat impulse spectrum over a bandwidth wide enough to cover a receiver bandpass centered at or near the original CW rf signal frequency. The characteristics of the pulsing signal, and the strictly rf parameters of the switch can be determined by steady state 
measurements. While the output pulse is not computed from physical parameters, it is related to other more easily made electrical measurements of the generating device. Again the spectrum can be calculated using the Fourier transform and an unknown generator compared using an arbitrary receiver. This method has been implemented in commercially available equipment although mismatch errors are not accounted for [3].

2. Measured Baseband Impulse Method.

In this approach the unknown impulse is measured by sampling techniques, e.g., a sampling oscilloscope, the data points digitized, and using the Fourier transform the spectral output is computed. Although this method is not new, recent advances in digital computers and sampling techniques have made it more practical. It was one of the methods used by the Power Section, Electromagnetics Division, NBS, to calibrate a solid state standard impulse generator [4]. Further refinements of the sampling and digitizing methods were made by the Pulse and Time Domain Section for a system to measure passive components by time domain techniques [5].

3. Measured Spectral Intensity Method.

(a) Voltage Measurement. This method makes use of the impulse response properties of certain types 
of networks where the peak response of the network to a CW signal can be related to the peak response to an impulse signal, by means of the impulse bandwidth of the network. A receiver whose impulse bandwidth has been measured is calibrated with a known CW signal whose frequency is set to the peak response of the receiver. The amplitude of the CW signal is adjusted to give the same peak response from the receiver detector as an unknown impulse. This amplitude combined with the receiver impulse bandwidth is taken to be a measure of the magnitude of the impulse signal at the frequency to which the receiver is tuned. To calibrate an impulse generator as a function of frequency, this procedure must be repeated at many points over the frequency range. One variation of this method is to use a fixed, stable, high Q network, followed by a broadband receiver (even an oscilloscope) as the detector. This permits the network impulse response to be more closely controlled although separate networks would be required for each frequency to be measured. This general method is probably the most used procedure for calibrating impulse generators because it is relatively easily made and does not necessarily require sophisticated or hard to obtain 
equipment. It is the on $1 y$ method, other than the fourier transform of the base band impulse, using readily available equipment, that will give the spectral intensity as a function of frequency over a large frequency range in a reasonable amount of time. However, there are several shortcomings to it, both practical and theoretical, as pointed out by M.G. Arthur [6].

(b) Power Measurement. Instead of measuring the spectral intensity directly in volts/Hz, it is possible to measure the spectral density in watts/Hz by radiometric means. The unknown impulse is compared against a thermal white noise source whose spectral intensity can be calculated very accurately. Then by knowing the repetition rate and the internal source impedance of the impulse generator it is possible to calculate its spectral intensity [7]. It is not necessary to know the bandwidth of the radiometer. This method is believed to be potentially the most accurate since modern radiometers can make very precise measurements which are then related to the physical properties of the thermal noise sources used as standards. Because of the complexity of the equipment, it is basically a narrowband technique, the measurement being limited to the design constraints of the radiometer. 
NBS chose to concentrate on methods $3(a)$ and $3(b)$ using the former to obtain the relative value of the spectral intensity as a function of frequency and the latter to establish the absolute value of this function at two selected frequencies.

\section{Accomplishments of Phase I}

The accomplishments of phase I have been discussed earlier [1] but are repeated here in outline form.

1. A sum and difference correlation (SDC) impulse radiometer was breadboarded for $30 \mathrm{MHz}$ and partially breadboarded for $1 \mathrm{GHz}$. Test data taken at $30 \mathrm{MHz}$ indicated good resolution although the dynamic range was limited. Only preliminary data were taken at $1 \mathrm{GHz}$. Block diagrams of these systems appear in figures 1 and 2 .

2. A programmable, swept EMC receiver covering $15 \mathrm{kHz}-$ $1 \mathrm{GHz}$ (hereafter referred to as receiver $\mathrm{A}^{*}$ ) was obtained for use as a relative spectral intensity measuring device which would be absolutely calibrated at $30 \mathrm{MHz}$ and $1 \mathrm{GHz}$ by the radiometric method. The unit purchased was one of the first production models and although preliminary testing indicated the unit was suitable for the purpose

*All commercial equipment referred to in this report is coded in compliance with NBS policy. For further information contact the Office of Director, National Bureau of Standards. 
intended, it was plagued with minor mechanical and electrical faults. In fact the unit was only fully operational during the last three months of this contract period.

3. Some of the theoretical aspects of defining impulse spectral intensity were examined. Although not all of the questions were resolved, the final report indicated which direction seemed to offer the most promise to put the definition on a firmer mathematical basis.

\section{Accomplishments of Phase II}

1. Continuous Frequency Coverage.

(a) Early in phase II, during further testing of receiver $A$, it was discovered that its bandwidth and its gain were a function of the frequency to which the receiver was tuned. For a receiver to be used in measuring spectral intensity, it is desirable that either its gain or bandwidth not be a function of frequency. It is relatively easy to calibrate out variations in one of these parameters (particularly gain) if the other remains constant. The manufacturer's specifications for receiver A implied a constant bandwidth but such was not the case. 
Since an impulse generator with known output versus frequency was not available, the receiver was measured at frequency values that were common to adjacent bands. For instance, a measurement at $25 \mathrm{MHz}$ on the high end of one band was compared to a measurement at $25 \mathrm{MHz}$ at the low end of the next higher band. The gains at the two frequencies were first adjusted to be the same by measuring a constant CW signal. Then, if the bandwidths were the same, two measurements of the same impulse signal should have been the same, any difference being proportional to the bandwidth difference. This experiment disclosed variations of up to $4.8 \mathrm{~dB}$ at band edge frequencies due to changes in impulse bandwidth (see table 1). At lower frequencies this is probably due to mistracking of overly high "Q" preselector stages while at very high frequencies differences in input VSWR between the two bands may also be a factor. Calibrating the bandwidth as a function of frequency was considered unprofitable. Besides being a tremendous amount of work, there was no guarantee that it would stay constant as the tracking might change with time. 
(b) This led to a search for a better receiver to satisfy the continuous frequency coverage requirement of the project. Since frequency tracking of the input stages was one of the suspected causes of the bandwidth changes, attention was focused on broadband input receivers. As mentioned earlier, the Power, Current and Voltage Standards Section of the Electromagnetics Division, NBS, had recently completed a project for the Army/Navy/Air Force JTCG-METCAL/ Calibration Coordinating Group which involved the construction of a solid state standard impulse generator. As part of the testing of the generator, they evaluated and used a newly developed, commercial, spectrum analyzer as an impulse receiver. This unit, hereafter referred to as receiver $B$, seemed to offer enough promise of constant bandwidth and improved input VSWR that a thorough evaluation was warranted.

The bandwidth of receiver $B$ was measured at selected points over the frequency range of $15 \mathrm{kHz}$ to $1 \mathrm{GHz}$. A frequency synthesizer was used as a source while the receiver was allowed to sweep, tracing out its own selectivity curve on an $X-Y$ plotter. The synthesizer was then stepped in frequency about $1 / 5$ the bandwidth and another sweep taken. This process was repeated many times giving 
rise to a series of curves as in figure 3 . Since the frequency steps were accurately known, these furnished a calibration which could then be applied to any one of the traces and, using numerical integration techniques, its equivalent impulse bandwidth computed. A receiver bandwidth setting of $3 \mathrm{kHz}$ was used from $15 \mathrm{kHz}$ to $2 \mathrm{MHz}$ and $300 \mathrm{kHz}$ from $1.5 \mathrm{MHz}$ to $1 \mathrm{GHz}$. The results of these tests appear in figures 4,5 , and 6 . The bandwidth variation was less than $\pm 21 / 4 \%$ over the entire range. The estimated measurement error was $\pm 1.5 \%$.

The gain was also measured at selected points over the range. As expected the receiver was not flat but the gain variation was less than $\pm 8 \%$, much less than has been experienced with typical EMC receivers. The gain plots are presented in figures 7,8 , and 9 .

(c) The one penalty that must be paid for these excellent characteristics in receiver $B$ is that there is an upper limit to the amplitude of the base band impulse that can be accommodated without compression and this limit is necessarily lower in a receiver with no input tuning. For a 0.35 nanosecond wide pulse this upper limit was measured at $70 \mathrm{~dB}$ above $1 \mu \mathrm{v} / \mathrm{MHz}$. This limits the dynamic range of the instrument to about 
$20 \mathrm{~dB}$ for usable signal to noise ratios although with digital averaging techniques this can be increased by $20 \mathrm{~dB}$ or more. A more complete description of a proposed system using this device is contained in a later section of this report.

Unfortunately receiver $B$ on which these tests were conducted did not belong to the project and was not available to be incorporated into a permanent calibration setup. Funding for the acquisition of another receiver had not been planned or budgeted, therefore it was decided to limit the effort to completing the work remaining on the sum and difference correlation radiometer at 30 and 1,000 $\mathrm{MHz}$. Without a receiver of the required quality, there was no means for obtaining the relative spectral intensity over the desired frequency range.

2. $30 \mathrm{MHz}$ and $1 \mathrm{GHz}$ Radiometers.

(a) At the end of phase I, a breadboard model of a $30 \mathrm{MHz}$ radiometer had been constructed and some work had been started toward a $1 \mathrm{GHz}$ unit. During phase II the system was completely rebuilt for increased stability and sensitivity. The sensitivity to a $1 \mathrm{~dB}$ change in impulse intensity for two different repetition rates is shown in figures 10 , 11, 12, and 13. This represents a significant 
improvement in null sensitivity for a given integration time over that reported at the end of phase I [8]. However, the dynamic range of the system was not increased and it is believed that some of the changes which were made to improve other parameters may have decreased the dynamic range slightly. (b) It is instructive to calculate the useful operating range of this type of radiometer given certain assumptions. The assumptions are:

(1) The lower useful limit is where the impulse power is equal to the thermal noise generated by the internal impedance of the impulse generator at room temperature $(300 \mathrm{~K})$. (2) The total power required to operate the multiplier (see fig. 1) is $10 \mathrm{~mW}$.

(3) The maximum available output voltage at the multiplier driver is 10 volts RMS before compression.

(4) The useful range of the $A G C$ is $26 \mathrm{~dB}$. The multiplier elements (thermocouples, thermistors or bolometers) cannot be matched closely enough to insure adequate linearity. For this reason the multiplier must be operated at a constant total power input from each channel which is 
maintained by an AGC 1oop. Other requirements of the radiometer demand phase matching within $\pm 1.5^{\circ}$ in the two channels. Although the AGC elements constructed have a $35 \mathrm{~dB}$ range with $<1.5^{\circ}$ phase shift tracking error, some of this range must be allowed as a safety factor for gain drift, aging, etc. This reduces the useful operating range of the AGC to something less than $30 \mathrm{~dB}$ and $26 \mathrm{~dB}$ was chosen as a conservative figure. The calculation is given as follows: For the minimum useful input signal we have

$$
k T B=\frac{\left[V_{s}(f)\right]^{2}}{2 R \tau} B
$$

where $\mathrm{k}$ is Boltzman's constant,

$\mathrm{T}$ is the absolute temperature $(300 \mathrm{~K})$,

$B$ is the bandwidth,

$V_{S}(f)$ is the spectral intensity,

$\mathrm{R}$ is the real part of source impedance of impulse generator, 50 ohms in this example, $\tau$ is the repetition period of the impulse signal, or $V_{S}(f)=\sqrt{\frac{2 R T k}{F}}$ where $F$ is the repetition frequency of the impulse signal. Substituting values,

$$
V_{S}(f) \text { in volts } / H z=\frac{0.643 \times 10^{-9}}{\sqrt{F}}
$$


$=\frac{0.643}{\sqrt{\mathrm{F}}} \times 10^{3} \mu \mathrm{V} / \mathrm{MHz}$

$=\left(20 \log _{10} 643-10 \log _{10} F\right) \mathrm{dB}$ above $1 \mu \mathrm{V} / \mathrm{MHz}$

$=56.16-10 \log _{10} \mathrm{~F}$

$=26.16 \mathrm{~dB}$ above $1 \mu \mathrm{V} / \mathrm{MHz}_{\mathrm{z}}$ for a $1 \mathrm{kHz}$ repetition rate.

If $10 \mathrm{~mW}$ is required at the multiplier, $2.5 \mathrm{~mW}$ will be supplied by the impulse signal at the minimum sensitivity point. (The unknown signal which in this case is $1 / 2$ white noise and $1 / 2$ impulse signal is nulled against an equal $\mathrm{CW}$ reference power. Also in this simplified analysis the effective input noise temperature of the radiometer which is less than $290 \mathrm{~K}$ is ignored.) Therefore $\mathrm{G}$ (max. required gain of radiometer) $=\frac{2.5 \times 10^{-3}}{\mathrm{kTB}}$

$$
\begin{aligned}
& G= 0.201 \times 10^{14} \text { or } 133.05 \mathrm{~dB} \\
& \text { or } \mathrm{G}^{\prime}=4.483 \times 10^{6} \text { voltage gain assuming a } \\
& 50 \Omega \text { input and output } \\
& \text { impedance. }
\end{aligned}
$$

If the maximum signal at the output is 10 volts then the maximum input signal without AGC is:

$$
\frac{10}{G^{T}}=2.231 \times 10^{-6} \text { volts. }
$$

Since the bandwidth of the radiometer is $30 \mathrm{kHz}$ this corresponds to: 


$$
\begin{aligned}
2.231 \times 10^{-6} \times \frac{10^{6}}{3 \times 10^{4}} & =7.44 \times 10^{-5} \mathrm{~V} / \mathrm{MHz} \\
& =74.4 \mu \mathrm{V} / \mathrm{MHz} \\
& =37.4 \mathrm{~dB} \text { above } 1 \mu \mathrm{V} / \mathrm{MHz} .
\end{aligned}
$$

This is the maximum input that can be handled before AGC. It also corresponds to the minimum level at about a $80 \mathrm{~Hz}$ repetition rate.

As AGC is applied the maximum impulse signal that can be handled is increased rapidly until the limit imposed by the AGC operating range is reached. Since the AGC must be set so that it begins to act at the lowest useful signal, the maximum useful signal can never exceed the minimum useful signal by more than the AGC range.

However other factors further limit the useful operating region. There is an upper limit determined by the bandwidth of the radiometer. Since the bandwidth must be greater than the repetition rate, we have arbitrarily set the upper limit of the repetition rate at $5 \mathrm{kHz}$ for a $30 \mathrm{kHz}$ bandwidth.

Another constraint on the AGC time constant also restricts the lower repetition rates which can be handled. Since the 10 volt output chosen in this example represents 2 watts in a 50 ohm load, this could overload the operating point of the multiplier by $2000 / 10$ or 200 times should a transient system 
oscillation occur. The only practical way to protect the multiplier elements from damage is to make the AGC 1oop fast enough to reduce the gain of the system to a safe point. On the other hand it cannot have too fast a time constant or at slow repetition rates it will fail to integrate the output of the AGC power detector and hold the average power input to the multiplier constant. Thus a compromise is necessary between available output swing, AGC time constant, and minimum impulse repetition rate. A rate of $50 \mathrm{~Hz}$ which will accommodate the majority of mechanical impulse generators was selected.

Figure 14 contains a plot of the various factors which limit the range of the SDC radiometer and its useful operating region. By comparing this with figure 15 which is a plot of the region where the sensitivity of the breadboard radiometer appeared optimum at $30 \mathrm{MHz}$, reasonable agreement between the predicted and actual operating region is observed. The experimental data were taken below $50 \mathrm{~Hz}$ by lengthening the AGC time constant although this is not considered a safe mode of operation. As mentioned earlier the rebuilt radiometer constructed 
during phase II did not appear to have as great a dynamic range as predicted although time did not permit detailed measurements of this parameter.

(c) $1 \mathrm{GHz}$ Radiometer.

(1) The $1 \mathrm{GHz}$ radiometer constructed during phase II did not operate nearly so well as the $30 \mathrm{MHz}$ unit. Besides reduced sensitivity caused by the higher effective noise temperature of the radiometer (which was expected) there was an instability problem possibly due to relative phase changes in the two channels. The effect of phase instability on the null condition of the radiometer is a function of the cosine of the phase difference between the signals in the two channels. A change in relative phase will cause an apparent change in the value of the signal being measured. It is believed that some of the shielding enclosures used to contain leakage from the various oscillators and amplifiers acted as high "Q" cavities at $1 \mathrm{GHz}$ and that room temperature changes acting on these enclosures produced significant phase shifts in various internal leakage signals. Due to the termination of the project for lack of funds these problems could not be investigated and solved. 
(2) In addition to the above-mentioned problem and the usual troubles in suppressing leakage, it proved extremely difficult to construct an adequate waveguide beyond cutoff attenuator for the $1 \mathrm{GHz}$ reference $\mathrm{CW}$ signal. Input and output matching and mechanical stability problems were major obstacles and the attenuator became a small research project in itself. Although they were ultimately solved and a satisfactory attenuator constructed, the data for which appear in table II, the effort required was much greater than had been planned and reduced the time available for the rest of the project.

A photograph of the combined $30 \mathrm{MHz}$ and

$1 \mathrm{GHz}$ radiometers appears in figure 16.

(d) Measurements with the SDC Radiometers. Although, at the cessation of work in June 1972 , the radiometers were not fully evaluated some comparisons were made with the NBS standard impulse generator. A comparison of the readings at two different levels at a $1 \mathrm{kHz}$ repetition rate is given below: 
(Levels given in $\mathrm{dB}$ above $1 \mu \mathrm{V} / \mathrm{MHz}$.)

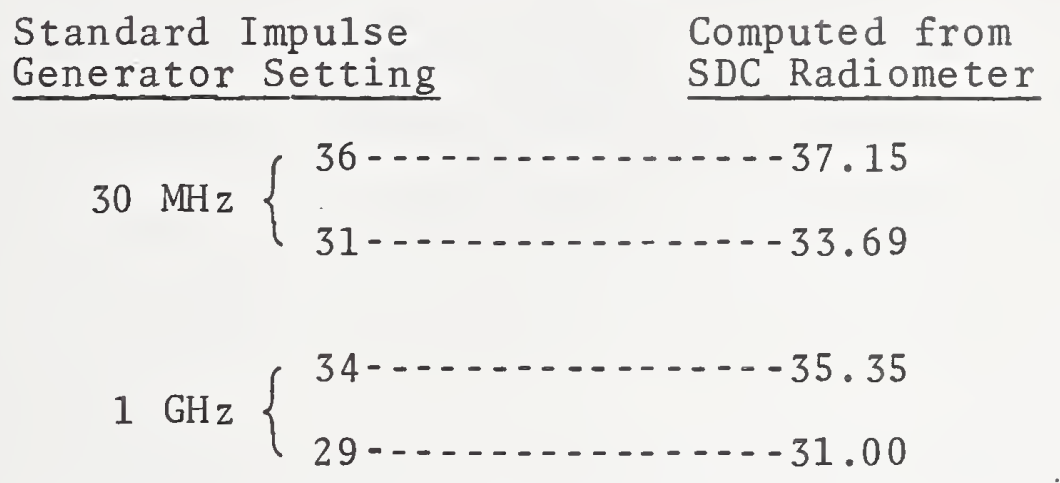

The estimated error of the standard impulse generator is $\pm 1 / 2 \mathrm{~dB}$. Since no error analysis was made for the radiometer and the values shown represent only a single determination, no firm conclusions can be drawn. It is interesting to note that the radiometric measurement is higher by 1 to $2 \mathrm{~dB}$ and a possible reason for this will be given in a following section in which solid state impulse generators are discussed.

3. $1 \mathrm{GHz}$ Thermal Noise Sources.

In order to use the SDC radiometer to calibrate an unknown generator it is necessary to have standard thermal noise generators at two different temperatures. The internal impedance of these generators must be adjustable to match the impedance of the unknown generator. Two thermal noise sources were already available at $30 \mathrm{MHz}$, but it was necessary to construct two more thermal noise sources at $1 \mathrm{GHz}$. The two temperatures were chosen 
to match those of the $30 \mathrm{MHz}$ units. They were boiling water or $373 \mathrm{~K}$ and the boiling point of liquid nitrogen $\left(\mathrm{LN}_{2}\right)$, or $77 \mathrm{~K}$. The method chosen to tune the generators' internal impedance is believed to be novel for this type of noise source. Varactor diodes were placed at predetermined locations along the transmission line from the source resistor to the outside connector but close enough to the resistor that they would be immersed in the temperature stabilizing medium. The $\mathrm{LN}_{2}$ itself acted as the cooling medium in the cold source. In the hot source a high boiling point (431 K), fluorochemical fluid* with a high thermal capacity was used. The temperature was maintained by a servo system using a thermistor sensor and heating resistors. Since all the possible noise generating lossy elements, including the basic source resistor, the tuning varactors, and most of the transmission line, are held at a known constant temperature the noise output can be accurately predicted. The internal temperature of both sources was monitored with precision platinum resistance thermometers. Figure 17 is an external view of the two sources while figures 18 and 19 show some of the internal construction of the hot and cold source respectively.

*Manufactured by Company " $\mathrm{C}$ ". 
The dials on the top of the sources control the voltages applied to the varactors for tuning. At $1 \mathrm{GHz}$ the cold source can match any impedance within a $1.2 / 1$ VSWR circle around the center of a $50 \Omega \mathrm{z}_{\mathrm{o}}$ Smith Chart while the hot source can match any impedance within a 1.3/1 VSWR circle.

The systematic uncertainties were evaluated for the two sources and are presented in the table below. The uncertainties are expressed in terms of temperature (Ke1vins) .

Source of Uncertainty

1. Platinum resistance thermometer calibration.

2. Thermal conduction along thermometer readout leads.

3. Calibration of the rmometer readout bridge.

4. Temperature gradients in baths.

5. Transmission line correction uncertainty.

Total uncertainty
$77 \mathrm{~K}$ Source $373 \mathrm{~K}$ Source

$$
0.066 \mathrm{~K} \quad 0.11 \mathrm{~K}
$$

$0.005 \mathrm{~K}$

$0.005 \mathrm{~K}$

$0.0001 \mathrm{~K}$

$0.001 \mathrm{~K}$

$0.01 \mathrm{~K}$

$0.01 \mathrm{~K}$

$0.15 \mathrm{~K}$

$0.10 \mathrm{~K}$

$0.2311 \mathrm{~K}$

$0.226 \mathrm{~K}$

Corrections for the electrical loss in the part of the transmission lines not immersed in the bath were calculated using a linear thermal gradient model. The 
corrections are listed below while the uncertainties in the corrections have been included in line 5 above.

\section{$77 \mathrm{~K}$ Source $373 \mathrm{~K}$ Source}

Correction due to electrical losses in transmission line.

$$
+0.262 \mathrm{~K} \quad-0.105 \mathrm{~K}
$$

4. Miscellaneous Work.

In testing the system during its development it was necessary to have a stable, repeatable, impulse source of variable repetition rate. While the better mechanical types may be repeatable, their repetition rate is not variable. A developmental solid state impulse generator was obtained on loan from Wright-Patterson Air Force Base and was used for all of phase $I$ and part of phase II. During phase II it had to be returned, and since the NBS standard impulse generator referred to before was not available on a day to day basis, it was necessary to find a substitute. An inexpensive, solid state comb generator for frequency calibration work had been developed by another group at NBS [9]. Since it was basically an impulse generator with about a 500 picosecond width whose repetition rate could be varied, a Fourier transform analysis was performed on its output. The impulse and the Fourier transform are shown in figures 20 and 21. As can be seen the output is relatively constant dropping 
on $1 \mathrm{y} 11 \mathrm{~dB}$ at $1 \mathrm{GHz}$. While this is not as flat as the better mechanical generators it is more than adequate for many purposes. The absolute output was not measured since it was not of great importance but was estimated to be $70 \mathrm{~dB}$ above $1 \mu \mathrm{V} / \mathrm{MHz}$. A schematic for the generator appears in figure 22. The significance of this data is that they demonstrate that a solid state impulse generator usable to $1 \mathrm{GHz}$ is not difficult or expensive to build. The cost of parts for the impulse generator not including the PRF driving source or power supplies) is under $\$ 50$. Any good laboratory pulse generator, or square wave generator with adequate rise time will drive it.

\section{E. Observations on Impulse Generators}

During the course of developing the measurement system many different types of impulse generators were employed as sources. Although the information which follows is mainly qualitative in nature it may be helpful to those unfamiliar with the instruments that are currently available.

1. Mechanical Switches.

Generators in this category generate impulses by discharging a section of transmission line with an electromechanical switch. The switch is driven by a low frequency oscillator $(50-2000 \mathrm{~Hz})$ which is sometimes 
adjustable. Impulses produced by such an instrument are subject to both phase and amplitude jitter and perhaps long term drift due to mechanical wear. In general they are not useful for semi-precision measurements nor worthy of precision calibration.

2. Mercury Wetted Switches.

These generators are similar to those described above except that the switch contacts are mercury wetted and the repetition rate is fixed and limited to $60 \mathrm{~Hz}$ or less. The absence of contact bounce and long term wear reduces the amplitude jitter and drift to an acceptable level although phase jitter is still present. This type of generator is the one most commonly in use today, either as a separate calibrator or built into EMC receivers as an internal calibrator. Although small mechanical variations will cause significant variations in output from unit to unit, they are individually worthy of precision calibration. Their phase jitter may make certain calibration schemes, e.g. those using sampling techniques, less useful.

3. Solid State Generators.

These generators use charge storage or step recovery diodes to generate a fast voltage transition. Such diodes retain stored carriers for a very short time after 
the terminal voltage changes from forward to reverse bias. When the charge is finally depleted an extremely rapid (as short as $50 \mathrm{ps)} \mathrm{transition} \mathrm{takes} \mathrm{place} \mathrm{from} \mathrm{the}$ short circuit to the open circuit condition. The rapid voltage rise across the diode is shaped by passive elements into a short pulse. Impulse generators using these devices produce spectra which have negligible amplitude jitter while phase jitter depends primarily upon the stability of the driving PRF generator. Accurate synchronizing signals are therefore available. A photograph of an oscilloscope display of the output of the solid state generator from Wright Patterson AFB referred to earlier is shown in figure 23. Either positive or negative output is available.

There is a problem which sometimes arises with solid state impulse generators. Because the impulse generating device must be driven at the required repetition rate by other circuitry, the driving signal waveform can leak through the step recovery diode circuit and appear attenuated at the output of the generator. Some of this leakage signal may be very close in time to the desired impulse in which case it appears as additional ringing on the output waveform. But other signals may appear much later in time, particularly if the driving waveform is a square wave. The amplitude 
of these extraneous signals may be quite small, < $1 \%$ of the amplitude of the main impulse, so that they are not often observed on an oscilloscope. If they occur after the response time of an EMC receiver, they will not produce a change in its peak reading meter display. But since their time duration may be quite long, their energy content approaches that of the main impulse at lower frequencies. Since a radiometer responds to the total energy within its pass band, not to the largest amplitude of the signal, the radiometric measurement would always indicate a higher value than measurement techniques which deal only with the main impulse and/or a receiver's response to it. This might be the cause of the measurements reported earlier with the SDC radiometer being about 1 dB greater than expected.

III. PROPOSED COURSE FOR FUTURE WORK

A. Planning Considerations

Several conclusions can be drawn from the work so far accomplished. First, it would appear that radiometric techniques, while having potentially high accuracy, are not desirable for general measurements of impulses. Radiometers measure total power and respond to artifacts between the major impulses which means they will be measuring something different 
than the typical impulse receiver which responds only to the peak amplitude of the largest signal appearing at its detector. It seems reasonable that a calibration system should measure that parameter of the impulsive signal which is most commonly useful for making measurements by other equipment. Further, when the impulsive noise source is at very low repetition rates, the power contained in the pulse train compared to the available power from the generator's internal source impedance results in poor signal power to noise power ratios. A radiometric technique would be of great value in cross-checking the accuracy of another type of impulse calibration system providing the impulse signal source used as a transfer standard is known to be free of artifacts and the repetition rate is kept high to maintain an adequate signal to noise ratio. Second, if an amplitude response system is to be used, it should be employed only as a means for comparing impulse generators since the theory that relates the receiver's absolute response to an impulse is based on measuring a quantity called impulse bandwidth which is not related rigorously to other more easily measured quantities. To develop a calibration service from this technique an impulse signal source must be developed that can qualify as a reference standard, which means its output must be calculable from physical constants and/or other electrical measurements. A baseband rectangular pulse generated by an electronic switch could be 
a candidate at low frequencies where its time duration can be accurately measured by digital techniques and its amplitude measured with the switch in the "on" position using D.C. instruments. At higher frequencies the RF pulse technique appears to be the only candidate which can satisfy the same criteria; name $1 y$, be calculable from its steady state electrical measurements. The criteria for selecting the operating ranges and characteristics of these generators are discussed in section $\mathrm{C}$ below.

Third, the measured value of the spectral intensity of available impulse generators is generally a function of frequency and depends in part on the reflection coefficients of the generator and calibration system. Therefore, measurements of these quantities must be made at closely spaced intervals in the frequency domain and appropriate corrections made. This necessitates that any practical calibration system must be automated, using computer control in the measurement process. Actually the mismatch problem affects the usage of the impulse generator in every application. It can be handled as mentioned above during the calibration, but it is almost universally ignored when the generator is used to calibrate other equipment such as field intensity receivers. A receiver which has been thus "calibrated" with an impulse generator is then connected to an antenna with unknown 
mismatch errors further degrading the usefulness of the original calibration. These problems concerning the application of impulse generators are beyond the scope of this report and are only mentioned to show that the problem is far from trivial.

B. A Newly Proposed System for Calibrating Impulse Generators

The former plan of using a SDC radiometer and thermal noise standards as a basis for providing a calibration service for impulse noise sources needs to be discarded and replaced with a more applicable and viable system. This section presents such a plan. The plan is an outgrowth of the work performed and the lessons learned from this effort.

Figure 24 shows a generalized block diagram of the newly proposed impulse calibration system. The basic components are a programmable receiver with low input VSWR and constant bandwidth (such as receiver B evaluated during this contract), a tracking generator which provides a CW signal which is automatically tuned to the center of the receiver's passband, a precision switch with on-off ratios $>70 \mathrm{~dB}$, a pulse generator, an impulse synchronized peak sample and hold detector with digitized output, an automatic network analyzer (to measure the complex reflection coefficients of the generators and the receiver), suitable RF switches, and a mini-computer. 
The system would function in the following manner. The automatic network analyzer would first measure the complex reflection coefficients of the standard generator, the unknown impulse generator, and the measurement receiver at as many frequencies as desired under the direction of the mini-computer. This data would then be stored in the computer memory. Next the standard generator would be applied to the input of the receiver. This will be a baseband pulse for frequencies up to $1 \mathrm{MHz}$ and a pulsed RF source for frequencies above $1 \mathrm{MHz}$. When the pulsed RF source is used, the RF source for the switch comes from the tracking generator, thus assuring the spectrum is centered with respect to the receiver. The computer tunes the receiver over the frequency range making measurements at the frequencies where the reflection coefficients were measured. The peak sample and hold device samples the output of the detector at the proper time to obtain the peak of the detected envelope. The instant of sampling is determined by a trigger pulse from the broadband directional coupler and a delay circuit which accounts for the receiver response time. The output of the sample and hold circuit is digitized and stored in the computer. To improve signal to noise ratios, from 100 to 10,000 measurements can be taken at each frequency and the computer performs a signal averaging, storing the averaged value before moving to the next frequency. When the measurements are finished, the computer calculates the measured spectral 
intensity relative to the standard, makes the necessary corrections to the raw values based on the reflection coefficients, and prints out the corrected values of spectral intensity vs. frequency. In this brief description many minor steps necessary to the operation of the automatic network analyzer have been left out since they are incidental to the measurement process.

\section{Proposed Standard Impulse Spectra Generators}

A rectangular baseband pulse of the type to be discussed produces a spectrum given by the Fourier transform [10]

$$
X(f)=A \tau \text { sinc } f \tau
$$

where $\operatorname{sinc}=\frac{\sin \pi f \tau}{\pi f \tau}$.

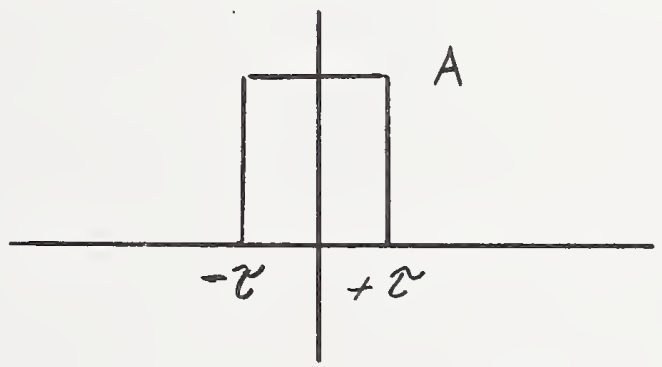

Since we will be dealing with pulse repetition rates slow enough that the measurement system response has essentially died away before the next pulse appears, it is legitimate to use the transform of a single pulse rather than the Fourier series. The sinc function is $\cong 1$ for small values of the argument and is reduced by $1 \%$ when the argument is $\cong 0.24$ and is reduced by $5 \%$ for an argument $\cong 0.55$. Hence for very 
short pulses ( $\tau$ very smal1), the impulse spectral intensity $S(f)$ is approximately equal to At. This expression, $S(f) \cong A \tau$, is commonly taken as the definition of impulse spectral intensity sometimes with the addition of a coefficient which we will assume is 1 . The difficulty with impulse generators using this principle is that in an effort to keep the spectrum flat to as high a frequency as possible $\tau$ is made so short that neither the shape nor amplitude can be predetermined and are extremely difficult to measure accurately. If it is desired that a spectrum be flat to $5 \%$ to $1 \mathrm{MHz}$, the situation improves greatly. The pulse width necessary is

$$
\begin{gathered}
.55=\mathrm{f} \tau \pi, \\
\text { or } \tau=\frac{.55}{\pi \times 10^{6}}=175 \text { nanoseconds. }
\end{gathered}
$$

This is a pulse length which can be generated and measured with an accuracy of better than $1 \%$. Using the fastest switching logic, rise and fall times can be less than 1.5 ns and the amplitude under the steady state "on" condition can be measured very accurately. Corrections for the 5\% rolloff at $1 \mathrm{MHz}$ can be computed along with second order corrections for the finite rise and fall times. Also since one pulse response must die away before the next pulse appears, there is an upper limit to the pulse rate. For the shape of passband in receiver $B$ it is necessary for the PRF $<\frac{\text { Bandwidth }}{1.7}$ for the response to have decayed to $1 \%$ of the peak value [11]. As a rule of thumb it is safe to make the $P R F \leqq \frac{B W}{2}$. 
Above $1 \mathrm{MHz}$ the switched or pulsed RF signal is more advantageous. The spectrum for this signal is [12]

$$
\begin{aligned}
X(f)= & 1 / 2 \text { A } \tau \operatorname{sinc}\left(f-f_{C}\right) \tau \\
& \pm 1 / 2 A \tau \operatorname{sinc}\left(f+f_{C}\right) \tau
\end{aligned}
$$

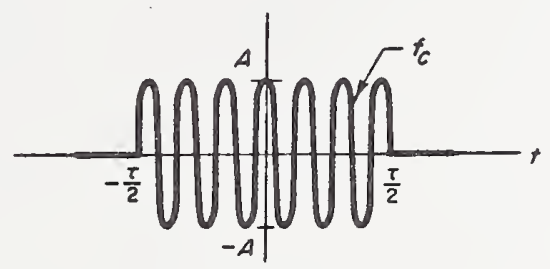

for a rectangular shaped pulse, where $f_{c}$ is the carrier frequency. Basically the spectrum shape is the same as that of a baseband pulse translated to the carrier frequency and symmetrical about it. The \pm before the second part of the expression depends on whether a cosine or sine function is chosen to represent the carrier signal.

Since we are really interested in frequencies about the center of the spectrum, $f_{c}$, the expression can be rewritten

$$
\begin{aligned}
X\left(f^{\prime}\right) & =1 / 2 A \tau \operatorname{sinc}\left( \pm f^{\prime} \tau\right) \\
& \pm 1 / 2 A \tau \operatorname{sinc}\left(2 f_{c} \pm f^{\prime}\right) \tau
\end{aligned}
$$

where $f^{\prime}$ is the frequency difference measured from the carrier $f_{c}$

Looking at eq. (5) and comparing it with eq. (2) shows that the first sinc function will contribute most of the expression's value at frequencies near the carrier while the second sinc function, sometimes called the "phase correction" 
[13], will become significant at frequencies well removed from the carrier. The requirement for one percent spectrum rolloff on either side of the carrier can be found from the first sinc function, e.g., for $150 \mathrm{kHz}$ on either side of the carrier (the widest bandwidth of receiver $B$ ) a pulse $<0.51 \mu$ second is required. The pulse repetition rate requirement is the same as for the proposed baseband pulse generator.

However, it is possible to choose the value of $\tau$ so that a whole number of rf cycles are included in the pulse (synchronous operation) or a nonintegral, irrational number of cycles (asynchronous operation). Since this will affect the spectrum through the magnitude of the phase correction, it is necessary to examine these conditions in more detail. Figure 25 is a plot of the phase correction expressed as a percentage of the basic "sinc" function, i.e.

$$
\because \text { Phase correction }=100 \times \frac{\operatorname{sinc}\left(2 f_{c} \pm f^{\prime}\right) \tau}{\operatorname{sinc}\left(f^{\prime} \tau\right)} \text {. }
$$

The carrie $\mathrm{r}$ frequency is $30 \mathrm{MHz}$ and $\tau$ was chosen to cover the region between 3 and 5 integral cycles of the carrier. The curve represents the percent correction at a separation f' from the carrier of $-150 \mathrm{kHz}$ which is $1 / 2$ the widest bandwidth of receiver $B$. The correction for $\mathrm{f}^{\prime}=+150 \mathrm{kHz}$ is of comparable magnitude. Figure 26 is the same type of plot except $\tau$ has been chosen to cover between 14 and 16 rf cycles. From these two plots it is evident that the spectrum amplitude can 
vary in asynchronous operation as a function of the number of rf cycles in the pulse with the variation decreasing as the number of $\mathrm{rf}$ cycles in the pulse increases. If at least 15 cycles are included in the rf pulse the variation will be less than $1.1 \%$ at $\pm 150 \mathrm{kHz}$, the widest $\mathrm{b}$ andwidth of receiver $\mathrm{B}$. This means that at $30 \mathrm{MHz}$ and above asynchronous operation is feasible if the pulse width is $\cong 0.5 \mu$ second. From 1 to $30 \mathrm{MHz}$ the pulse could be lengthened. This would also require a narrower bandwidth since the spectrum would fall off faster on each side of the carrier. Synchronous operation offers some advantages however. Table III shows the percent phase correction for integral numbers of cycles at various carrier frequencies and at different spacing, $f^{\prime}$, from the carrier. This table shows that at a given $f_{c}$, the phase correction is independent of the number of cycles in the rf pulse providing these are exactly a whole number of cycles. Keeping the criterion of a phase correction less than $1.1 \%$ and spectrum rolloff within the receiver bandwidth, the following chart can be made showing the parameters of the calibration signals. 


\section{Summary}

The calibration system which has been outlined represents what is believed to be a practical, state-of-the-art approach to the problem. It differs from the system originally proposed in that a radiometric measurement is not made on the unknown generator. While this represents some change in philosophy, it would not be possible except for the tremendous progress which has been made in automated measurements and in stable, programmable laboratory receivers and spectrum analyzers. Despite the fact that the project did not result in a completed set of hardware for the system described, enough has been learned to point the way to a practical calibration approach capable of being used at frequencies up to $1 \mathrm{GHz}$ and in principle even in the microwave region. 


\section{ACKNOWLEDGMENTS}

The author wishes to express his thanks to the following persons who at one time or another were connected with the project:

M.G. Arthur, for developing the background and theory of the SDC radiometric measurements while project leader during phase $I$.

L.D. Driver, for acting as project engineer during extensive periods of phase II and for developing the $1 \mathrm{GHz}$ thermal noise standards.

E.E. Baldwin, for constructing much of the electronic equipment used during the project.

A.R. Ondrejka and L.D. Martin, for making the measurements on the receivers which were evaluated.

E.B. Larsen, for offering many useful suggestions on RF pulse calibration. 
[1] M.G. Arthur, "Standards and measurement of impulse spectral intensity," Unpublished NBS Report, Oct. 1969.

[2] M.G. Arthur, "Impulse spectral intensity calibration at the National Bureau of Standards, Proc. 1969 Dept. Defense Electromagnetic Compatability Symposium, pp. $133-138$.

[3] "Calibration of impulse spectral intensity using pulsed CW signals," Andy Hish Associates, Tech. Report 0-0570101,5 pages, 1971 .

[4] A.R. Ondrejka, "Development and evaluation of a solid state impulse generator," Unpublished NBS Report.

[5] W.L. Gans and N.S. Nahman, "Fast fourier transform implementation for the calculation of network frequency domain transfer functions from time domain waveforms," NBS Interagency Report 73-303, Final Report DoD Calibration Coordination Group Contract 72-65.

[6] Op. cit. [1] pp. 4-5 .

[7] Op. cit. [1] pp. 24-35 .

[8] Op. cit. [1], p. 45 .

[9] J.R. Andrews, "A frequency calibrator for UHF using an avalanche transistor," QST, Vol. LVI, No. 5, pp. 16-18, May 1972 .

[10] A.B. Carlson, "Communication systems, an introduction to signals and noise in electrical communication," McGraw Hill, p. 31, 1968.

[11] "Spectrum analysis -- pulsed RF," Application Note 150-2 Hewlett Packard, p. 11, Nov. 1971.

[12] Op. cit. [10], p. 39 .

[13] "The frequency spectrum for a tone burst," Instrument Notes IN-105, General Radio Company, July 1965. 


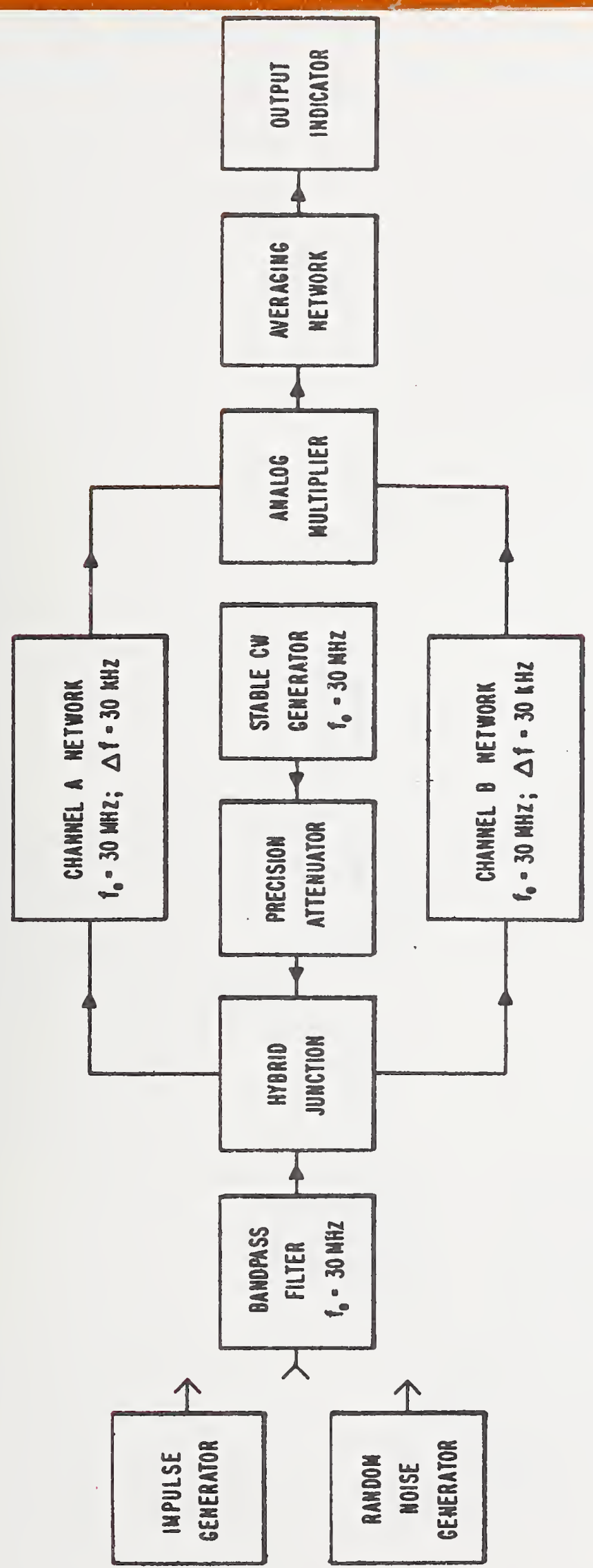

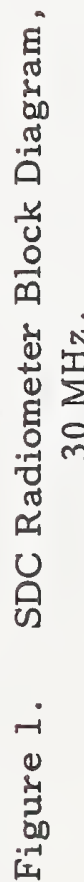



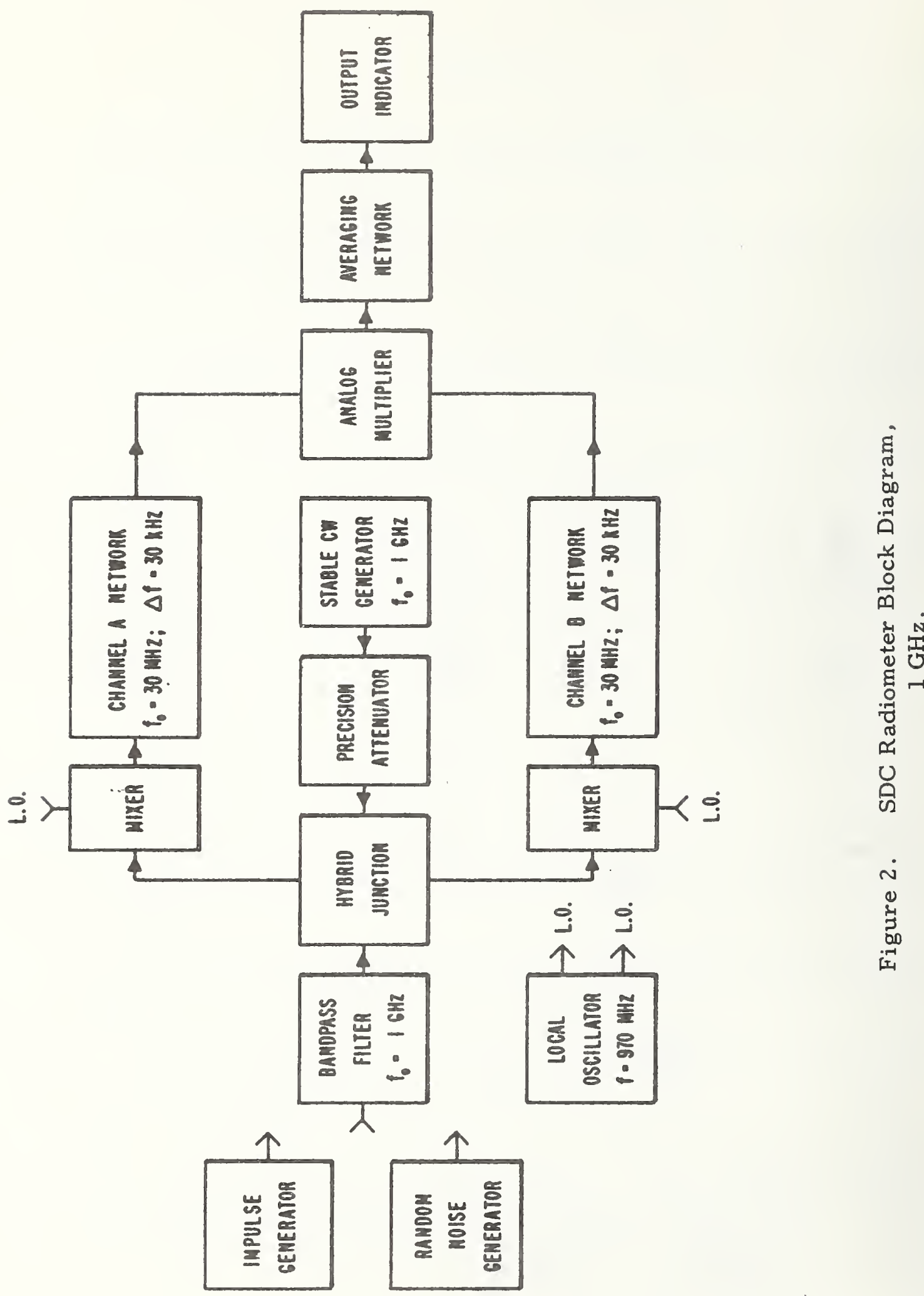


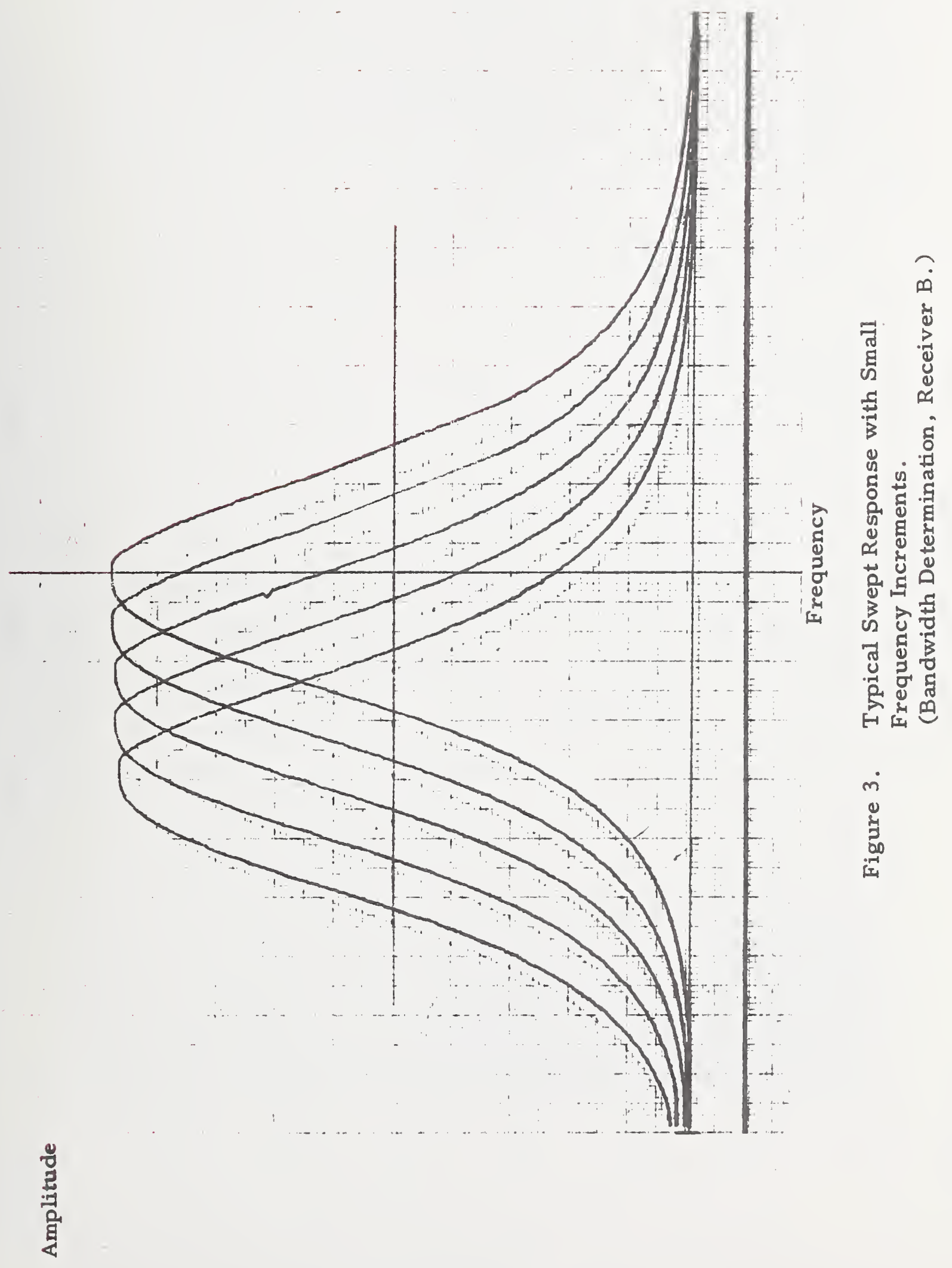




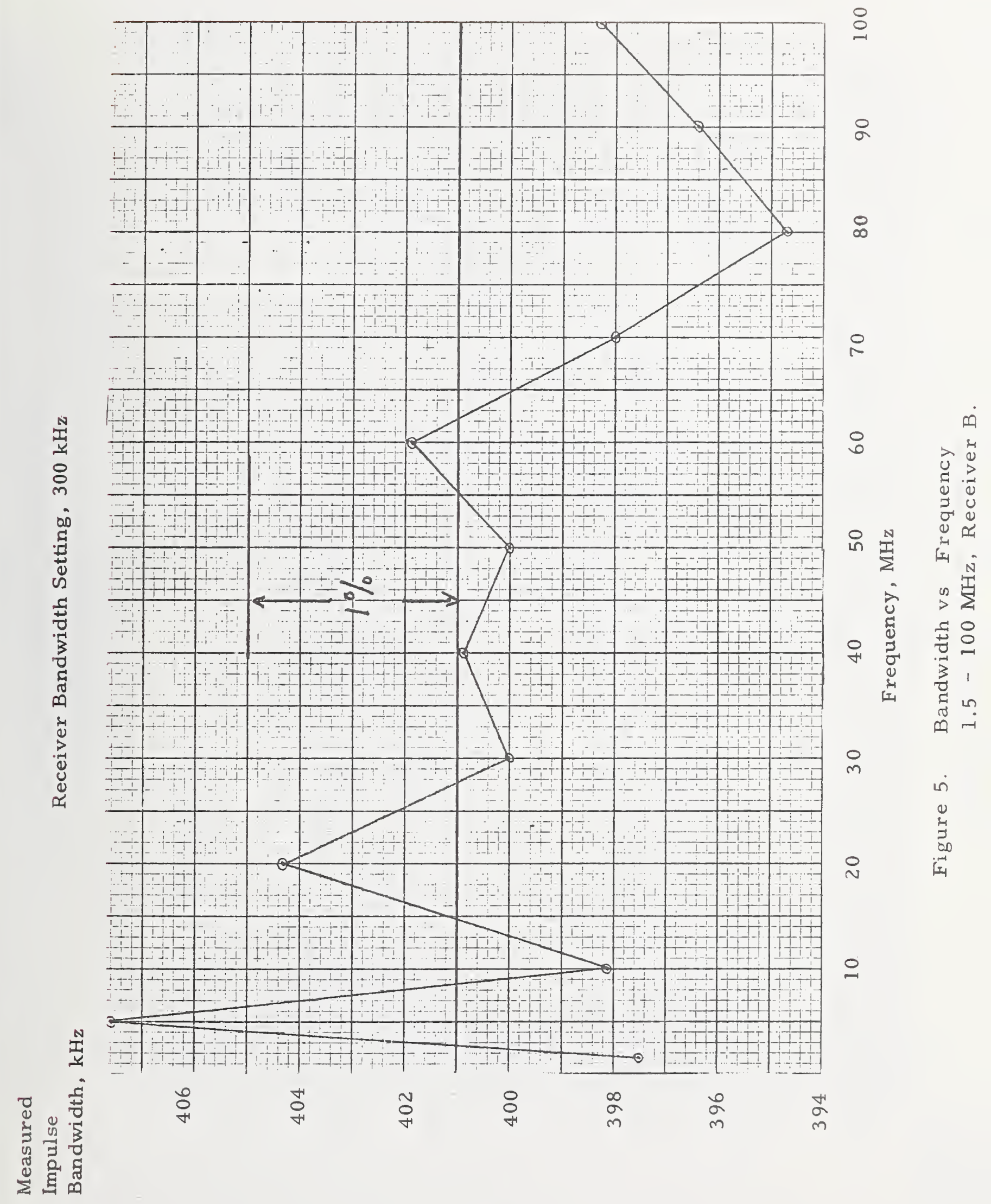




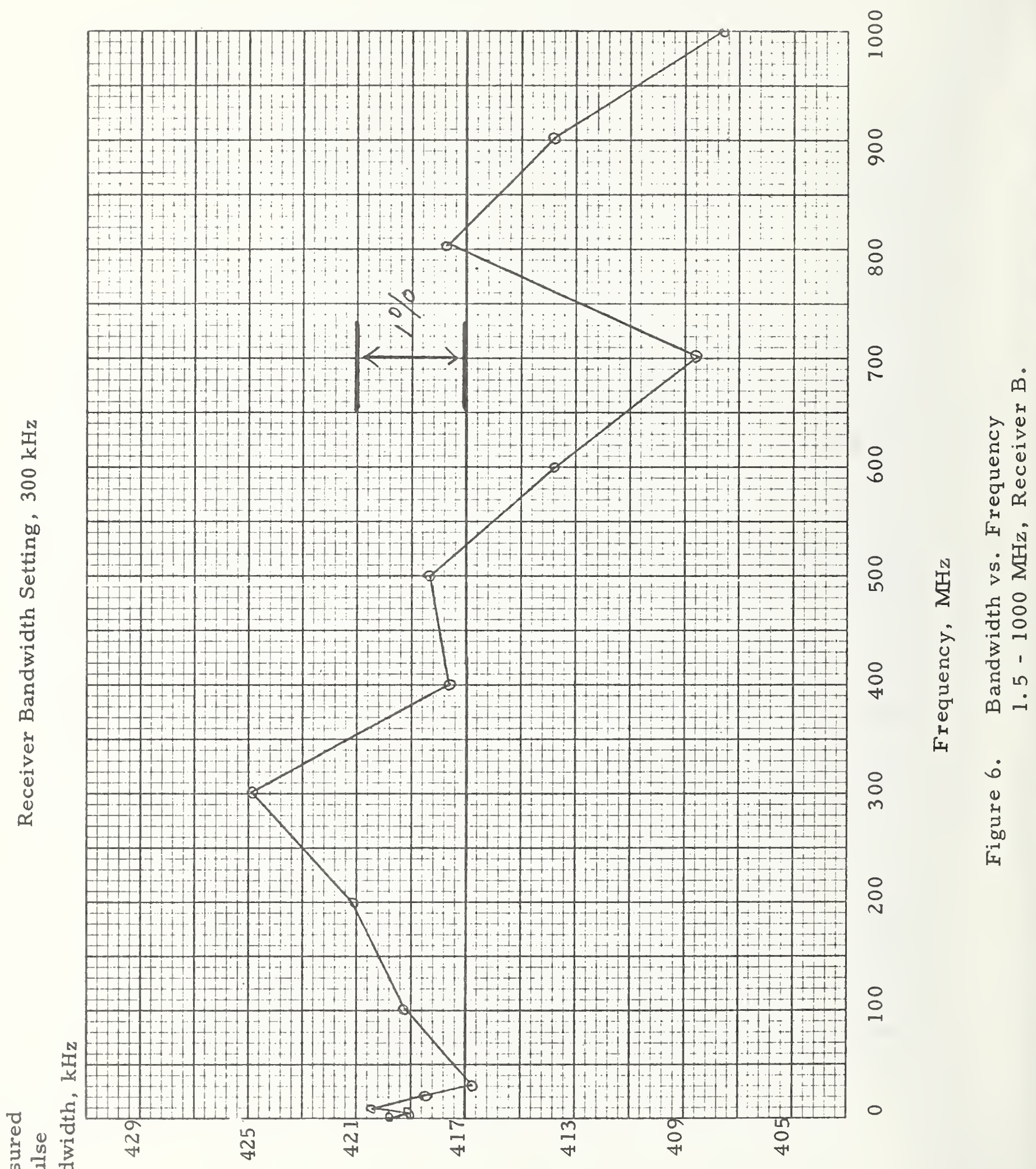




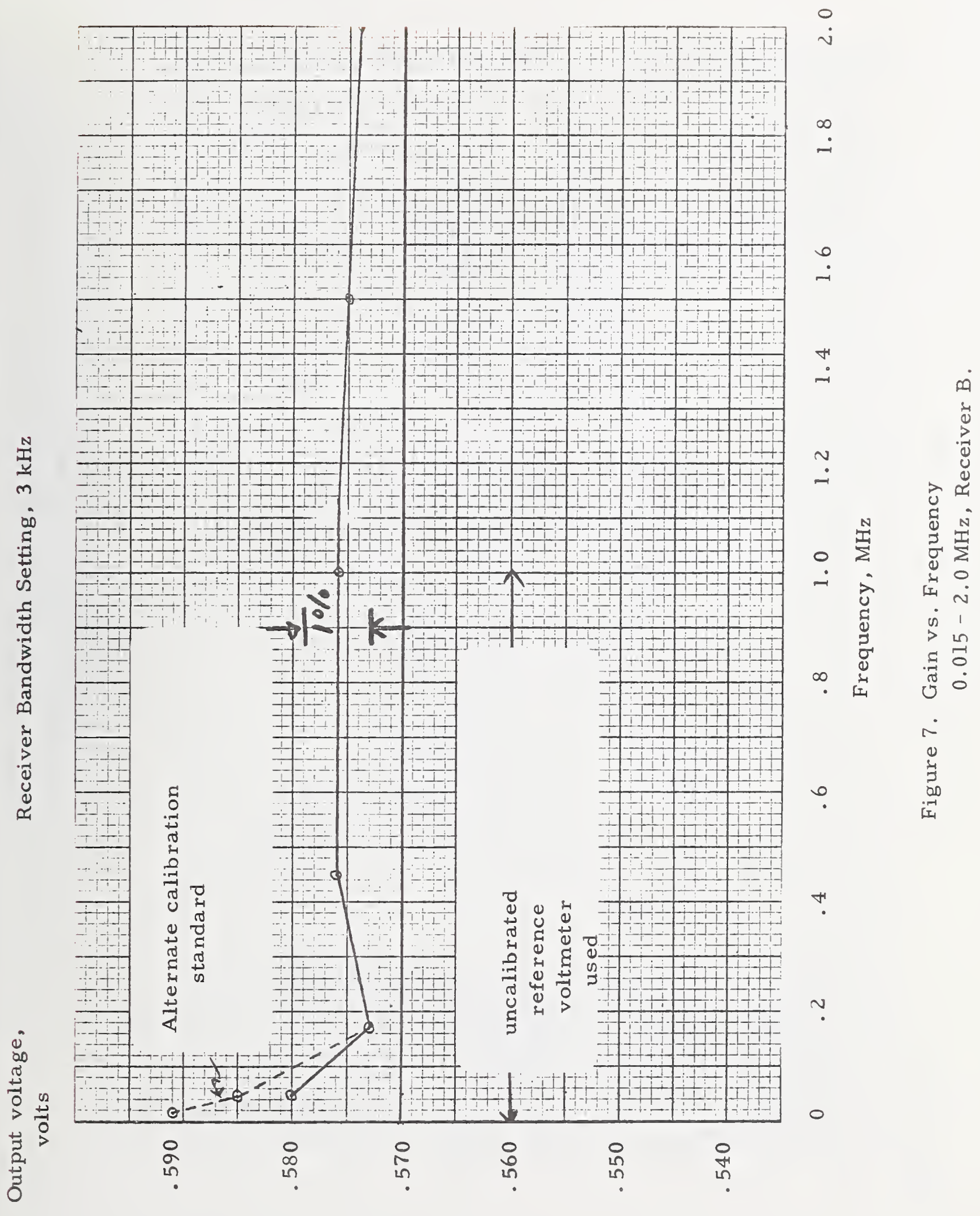




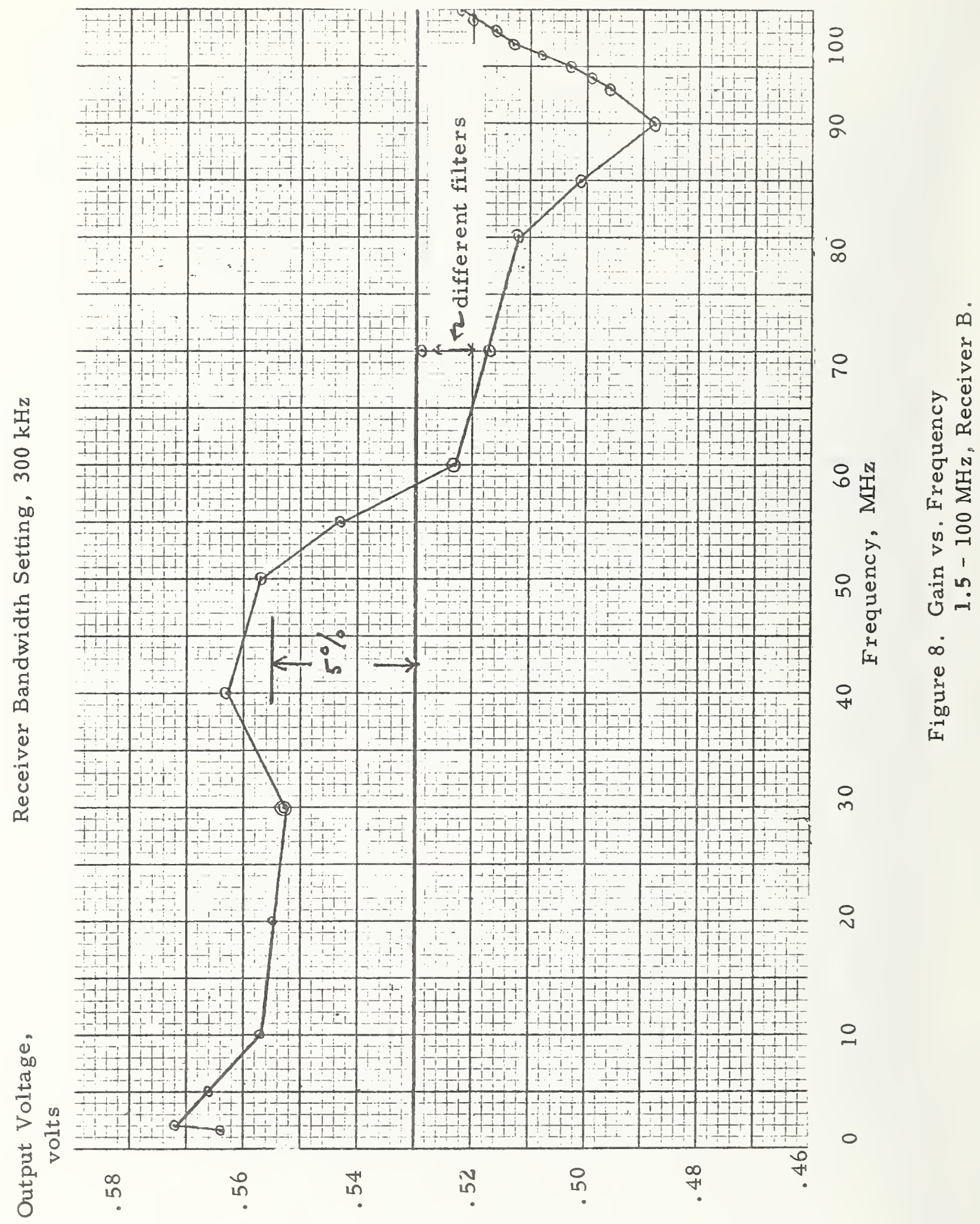




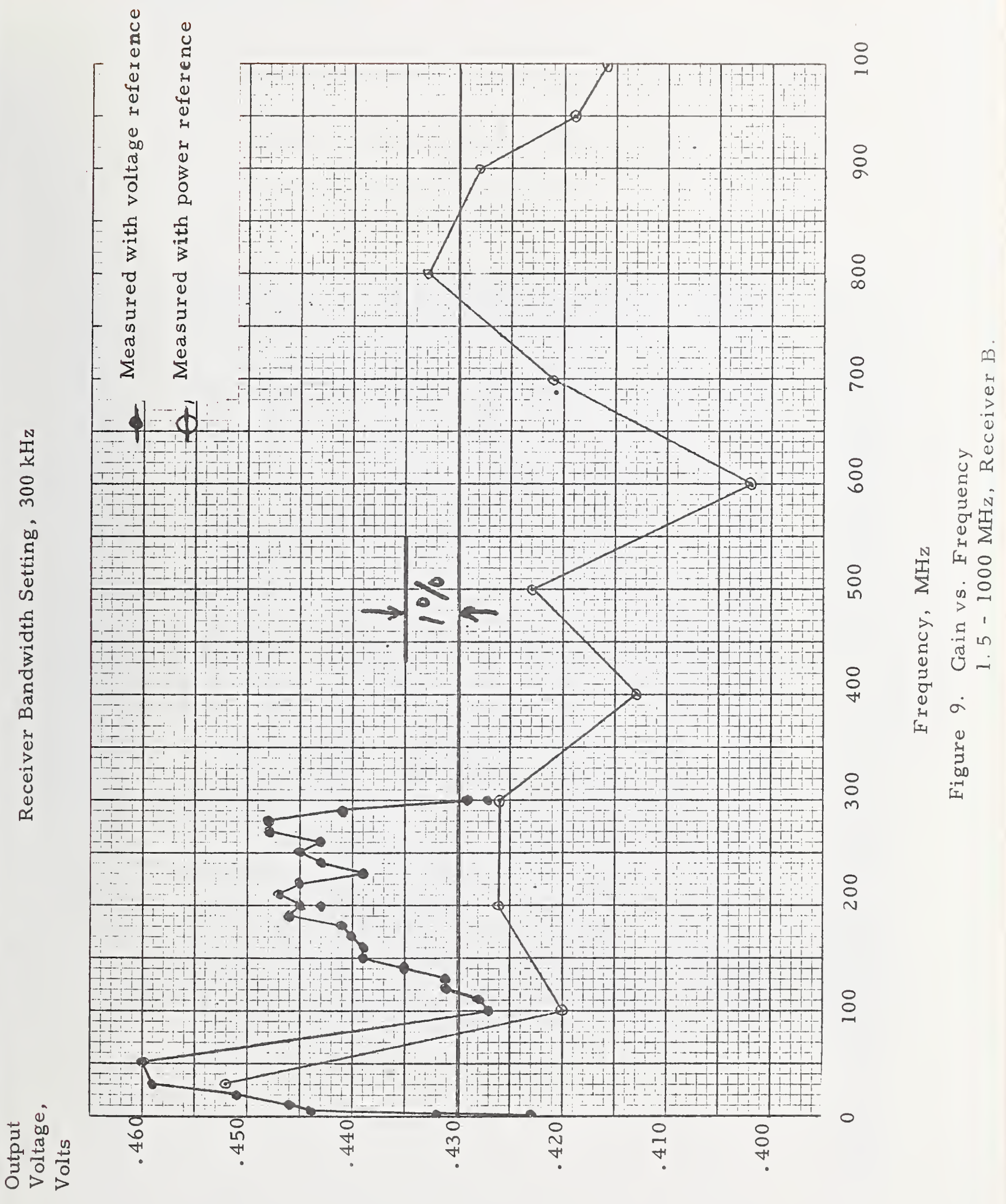




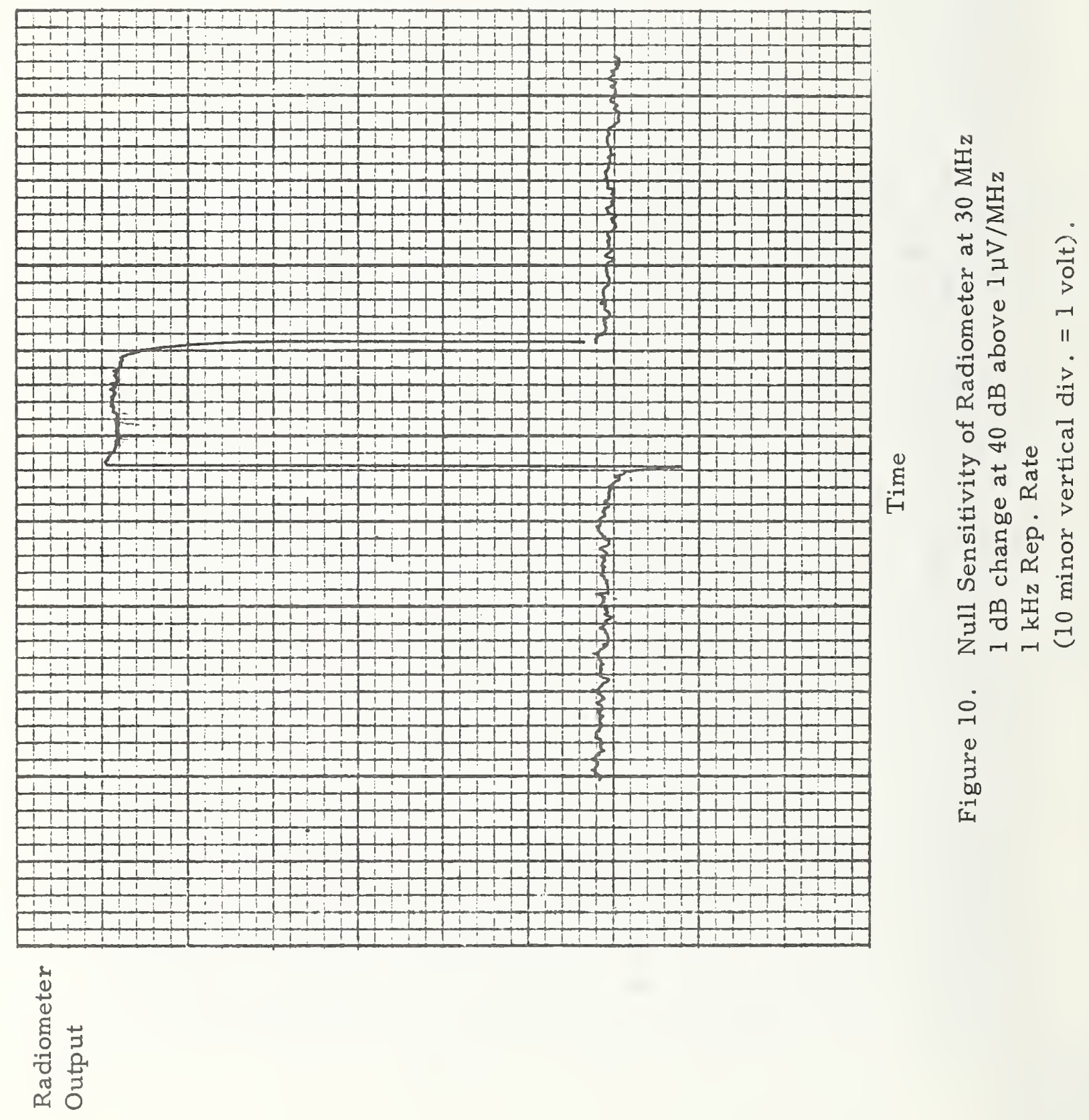




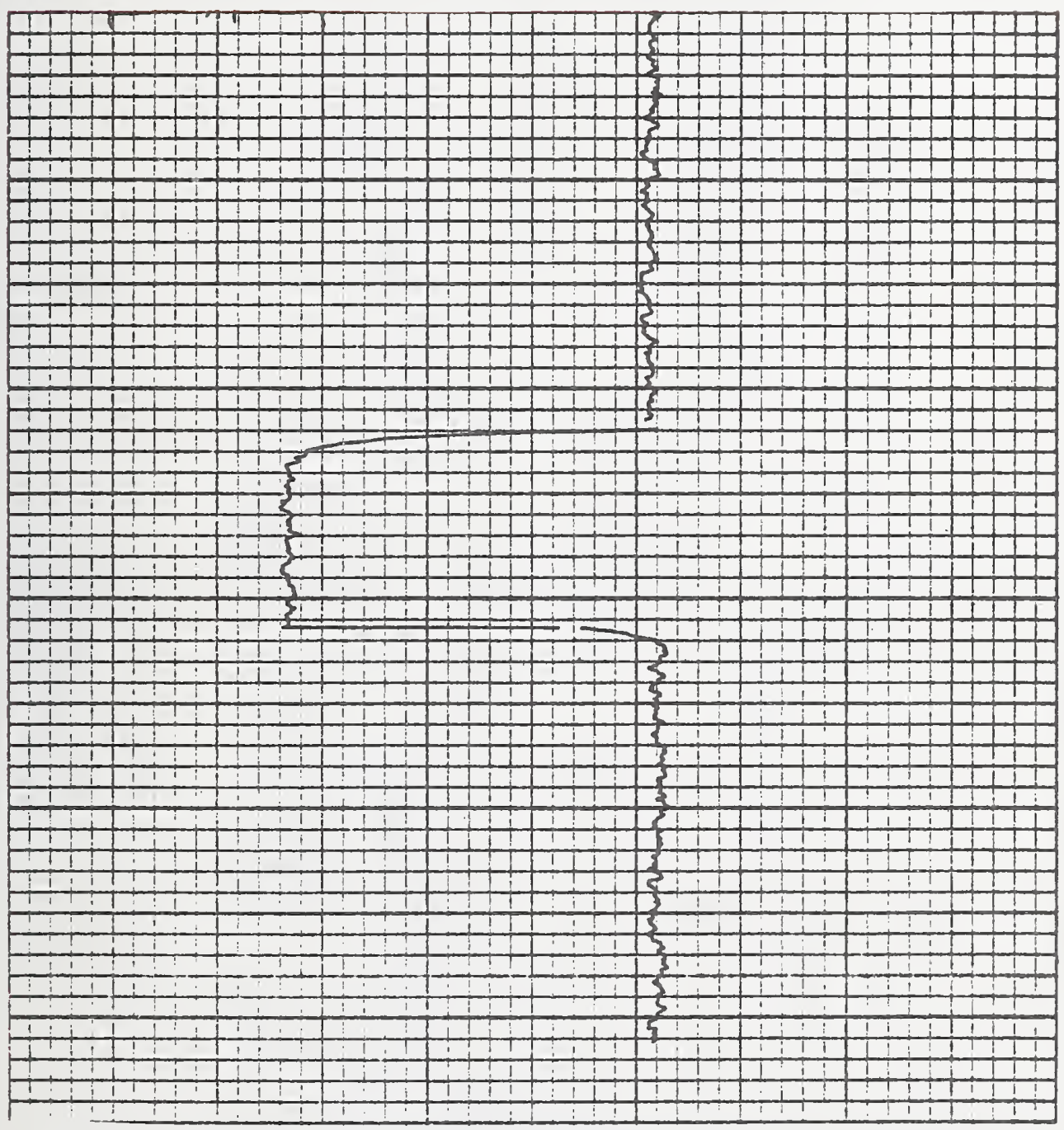

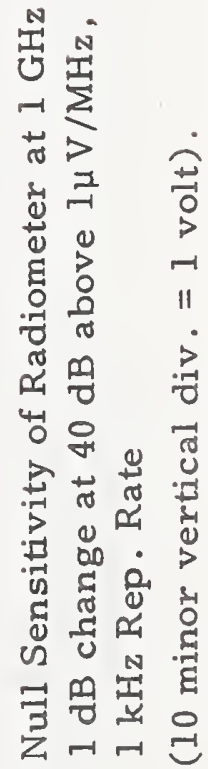

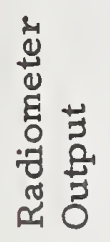




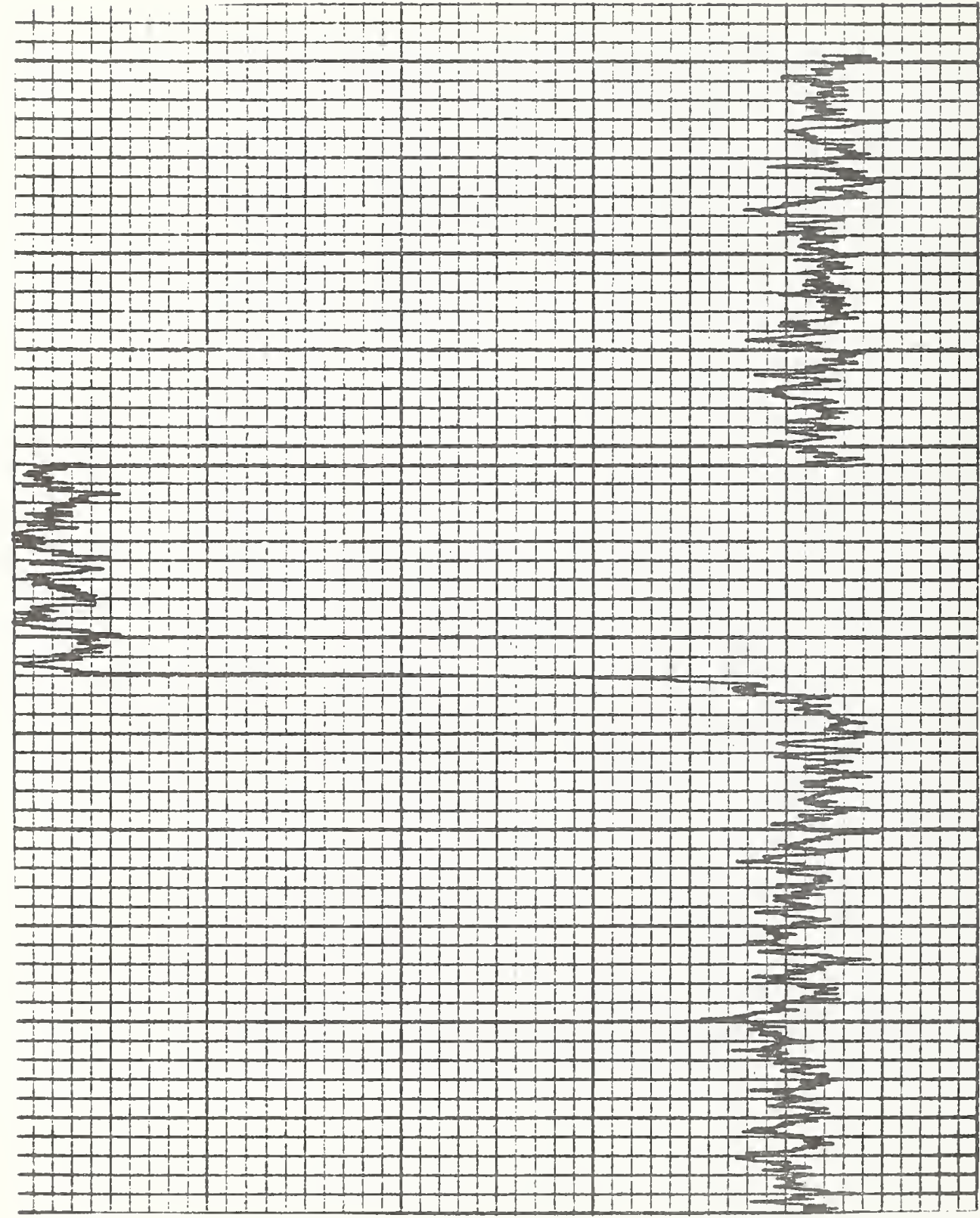

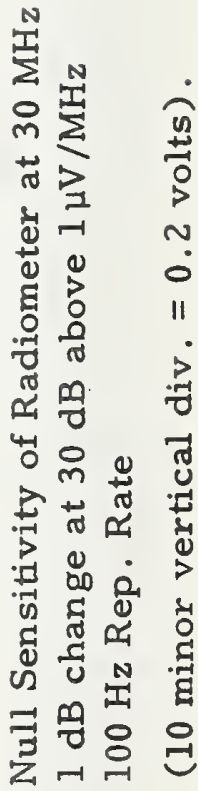

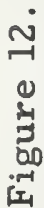

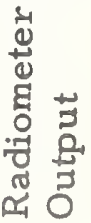




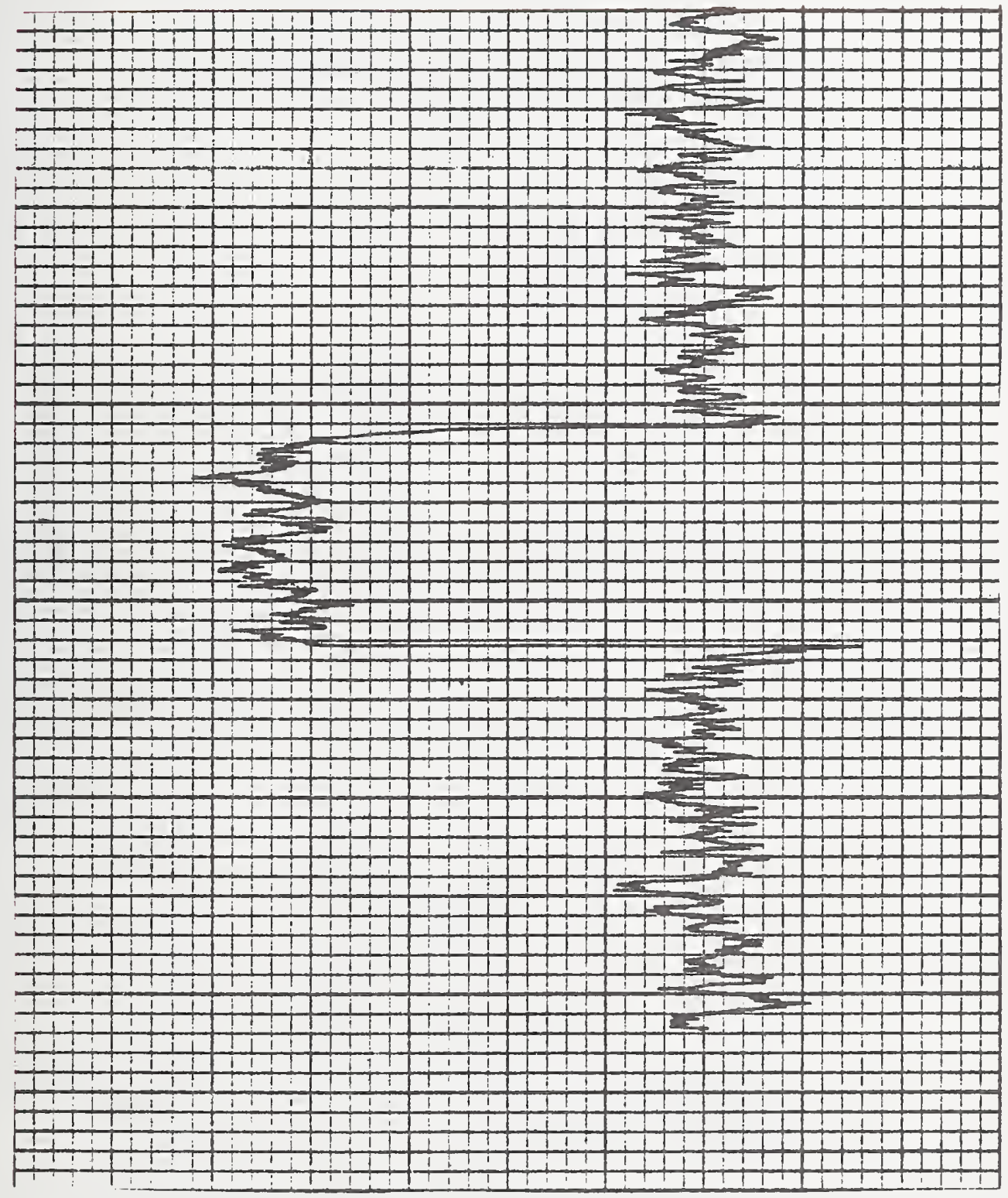

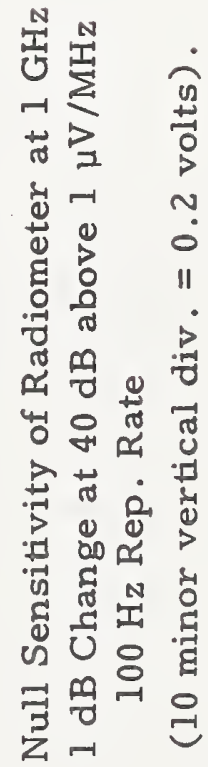

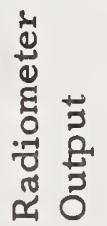




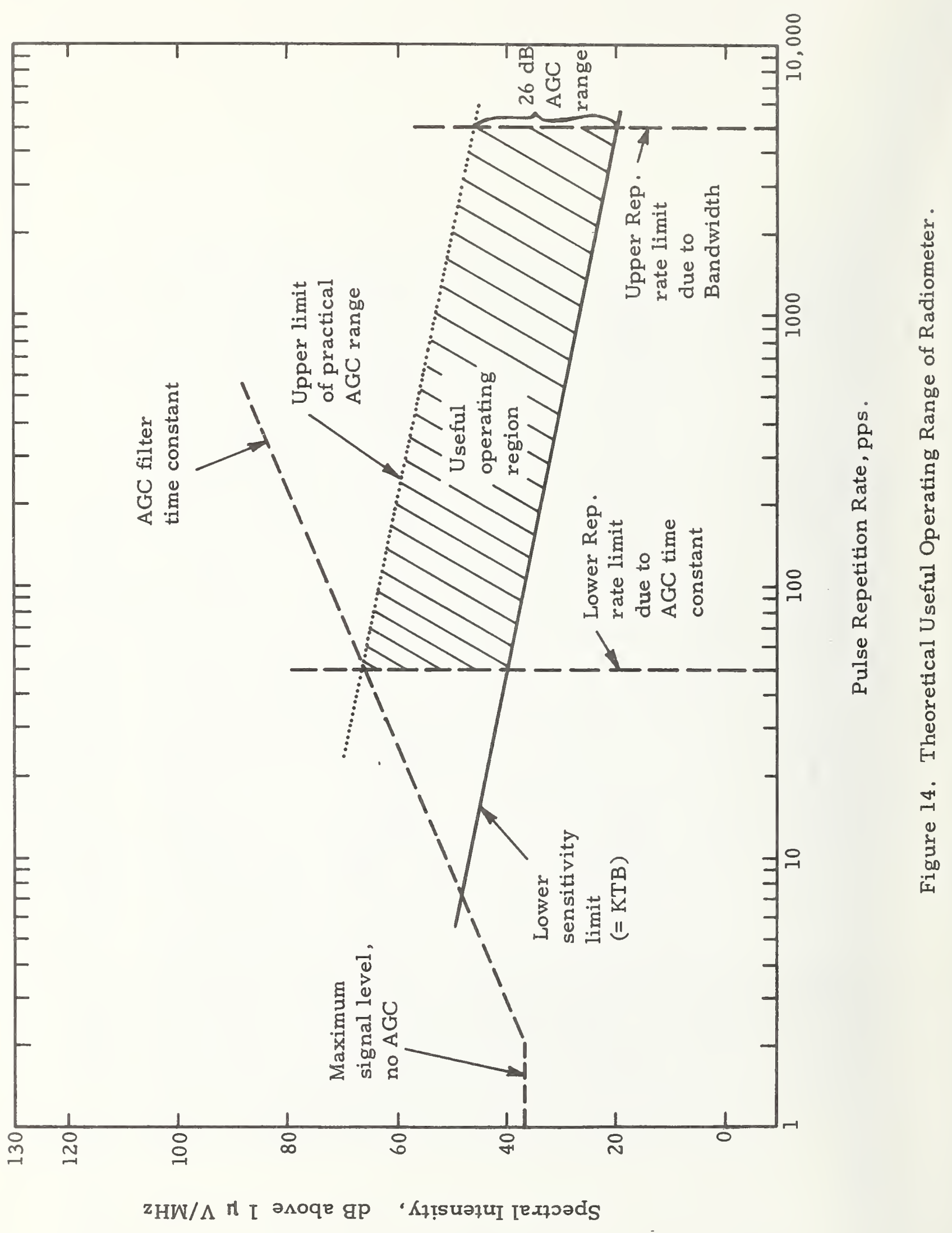




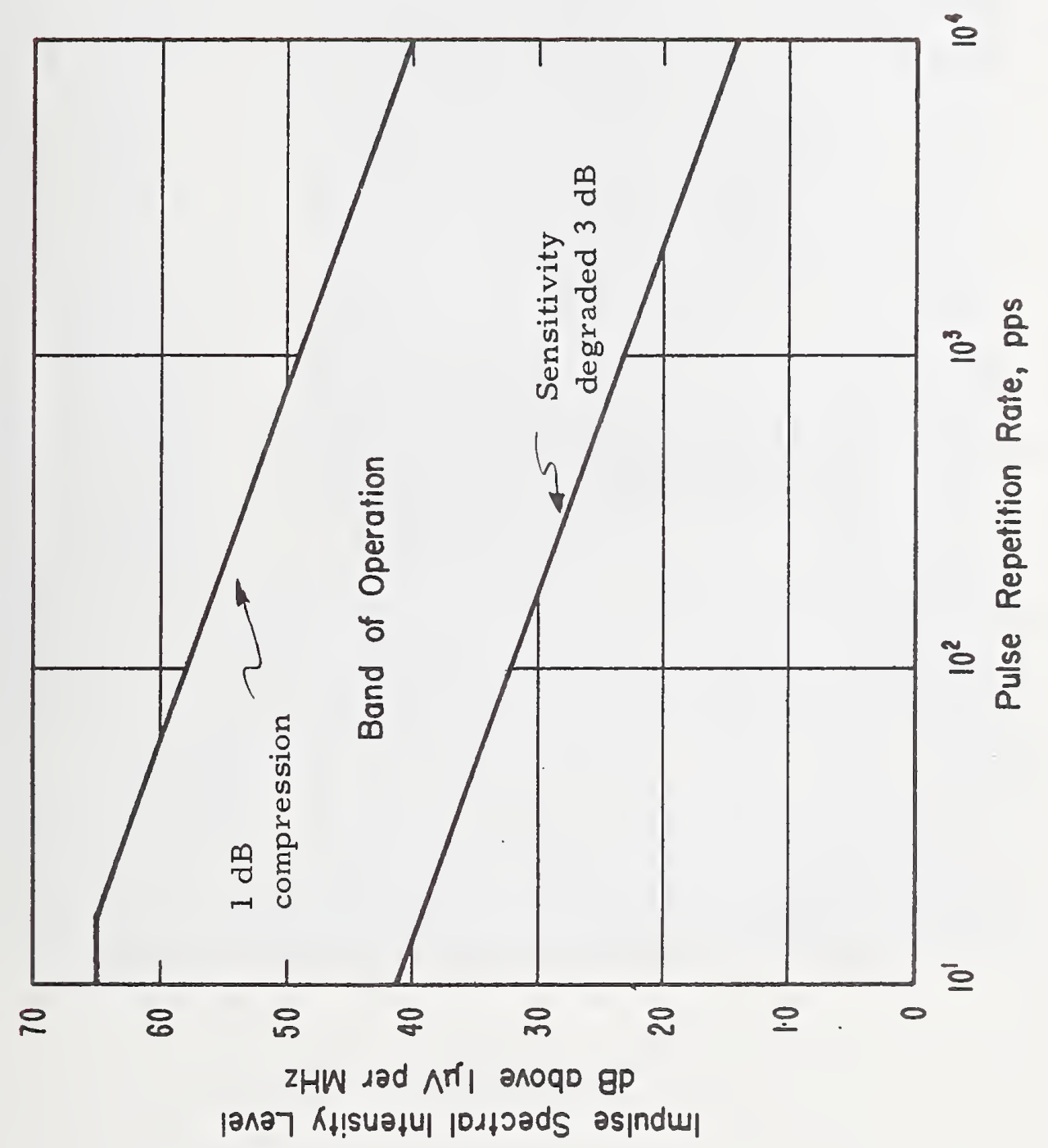

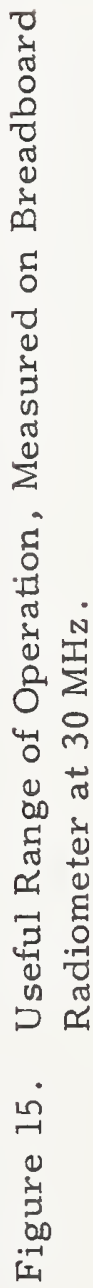

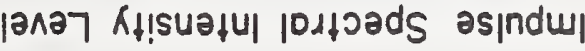




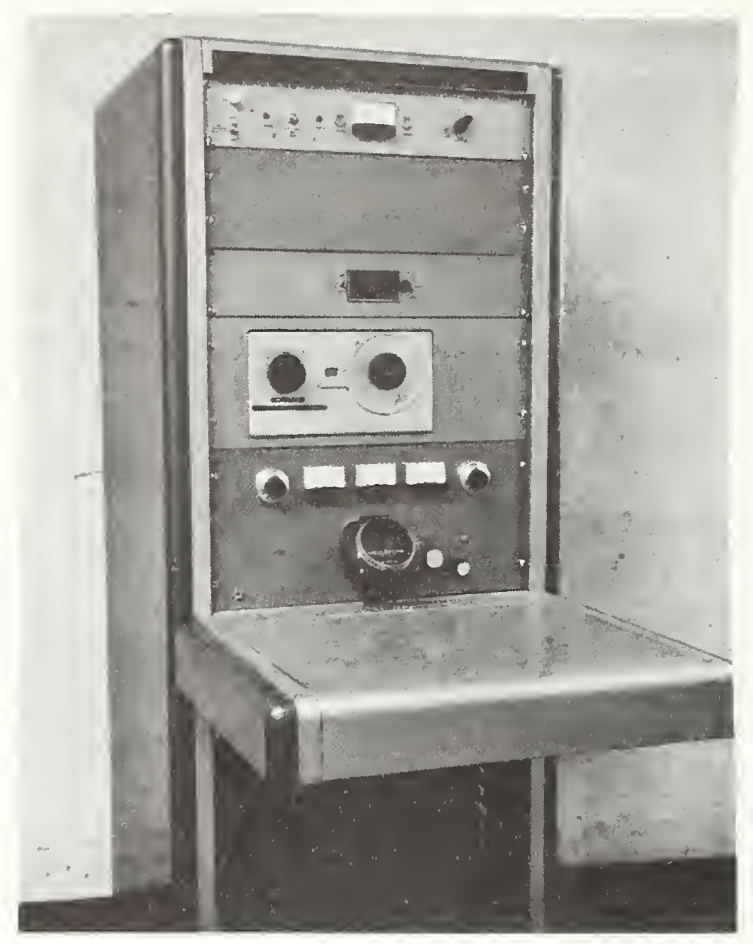

Figure 16. Sum and Difference Correlation Radiometer, $30 \mathrm{MHz}$ and $1 \mathrm{GHz}$, Phase II. 


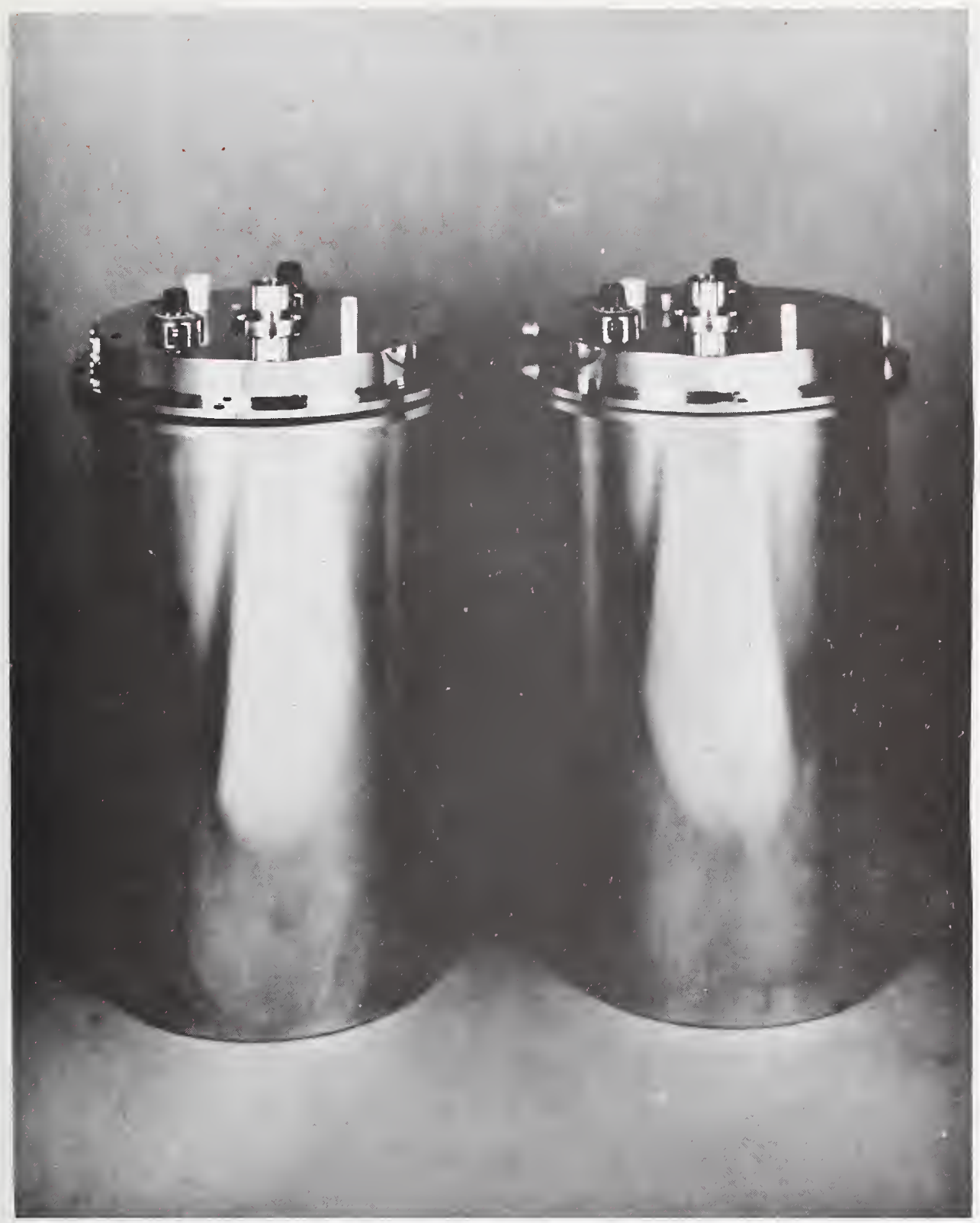

Figure 17. $1 \mathrm{GHz}$ Hot and Cold Thermal Noise Sources. 


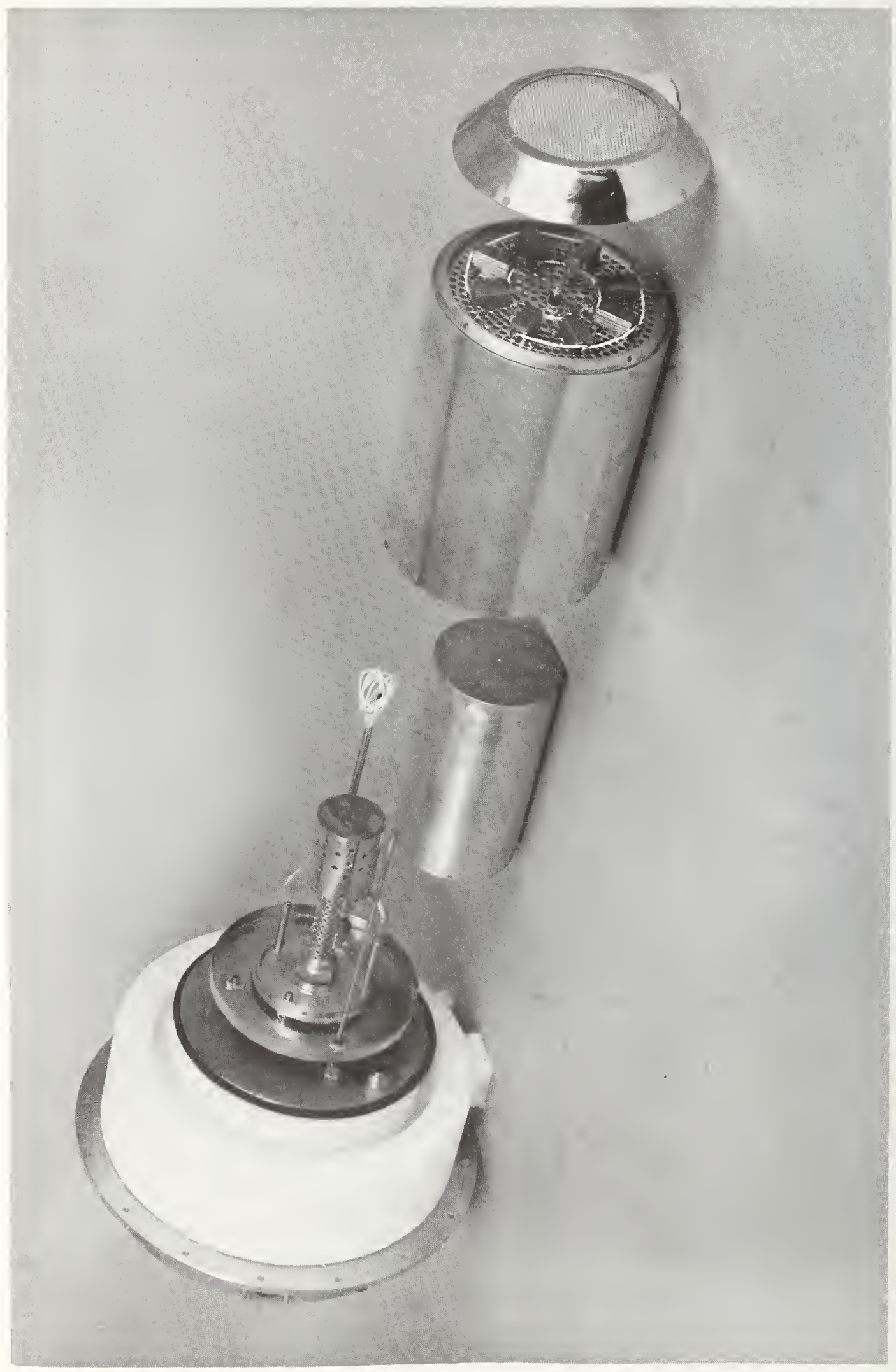

O 


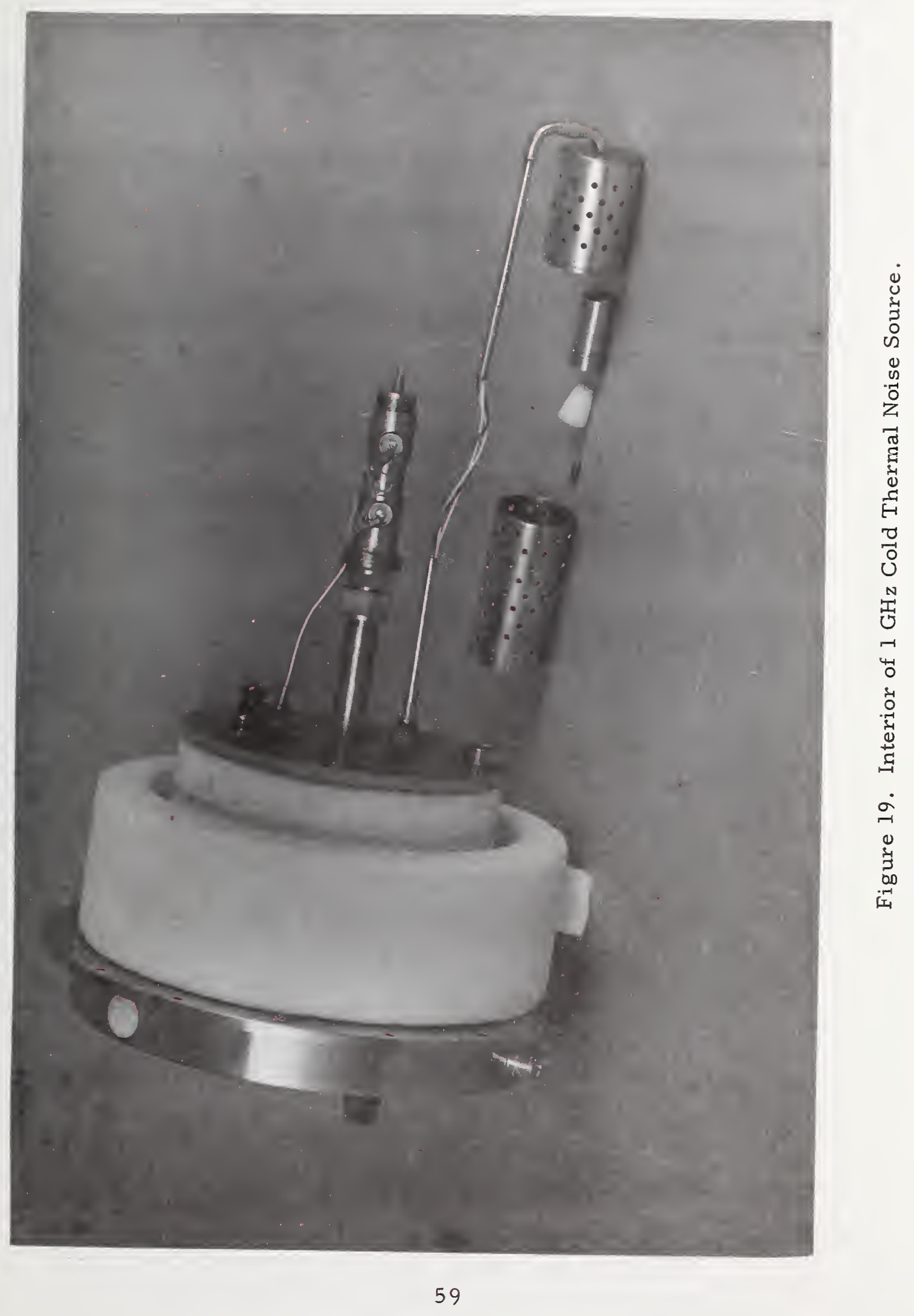




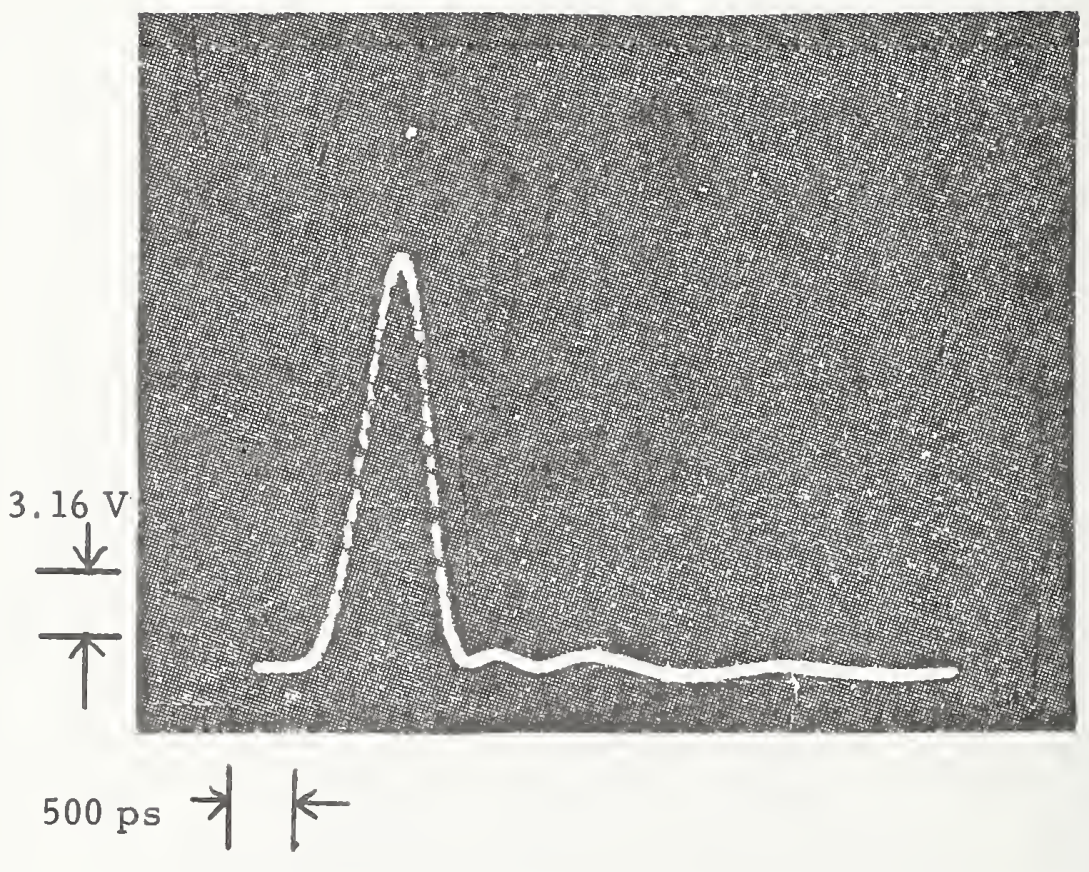

Figure 20. Impulse Produced by Avalanche Transistor Comb Generator. 


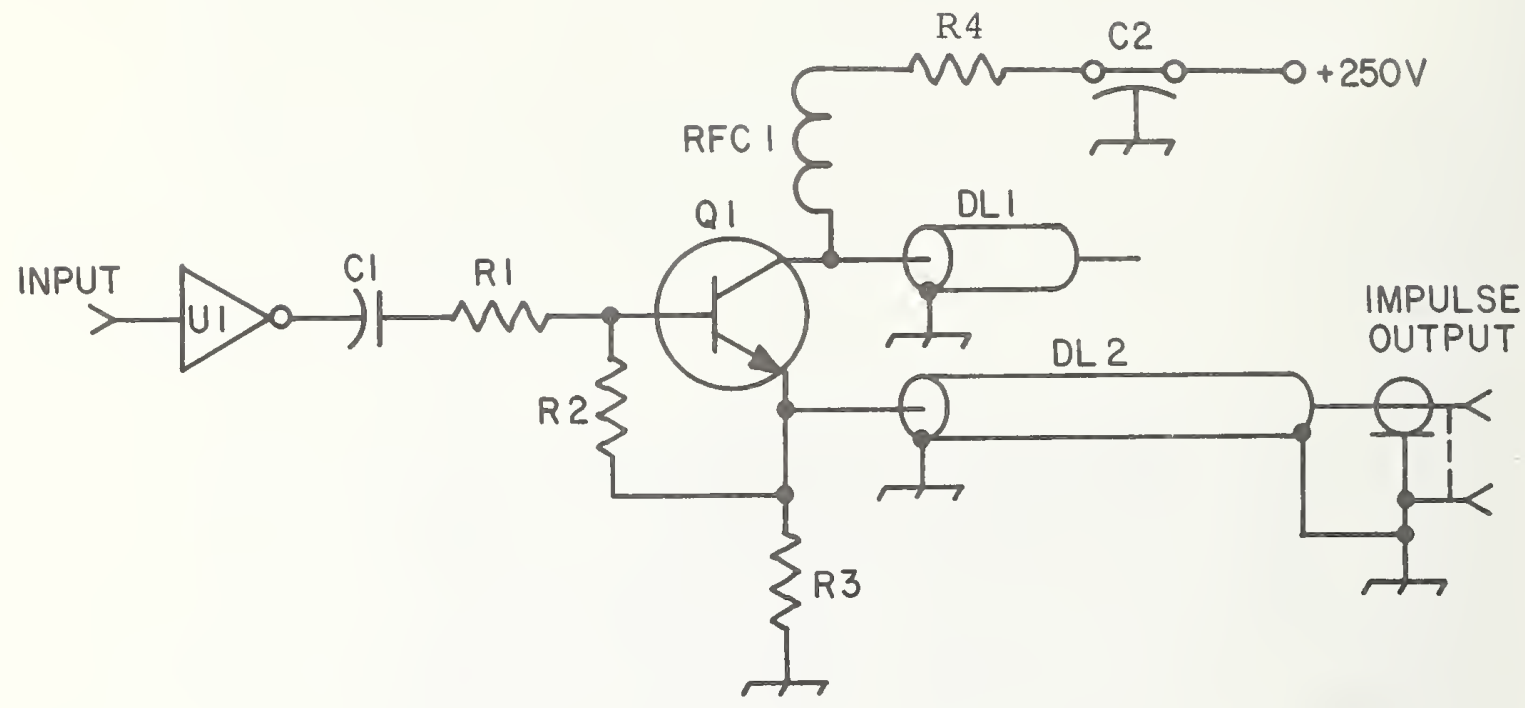

Cl $-47 \mathrm{pF}$, dipped mica.

C2 - $1500 \mathrm{pF}, 500 \mathrm{~V}$ feedthrough.

DL1 - 50-ohm microstrip transmission line.

DL2 - 50-ohm microstrip transmission line.

Q1 - 2N3904

R1, R2 - 100 ohms, 1/8 W.

R3 - Two 100-ohm, 1/8 W resistors in parallel.

R4 - 100,000 ohms, 1/2 W.

RFCl - Ferrite bead on R4 lead.

U1 - TTL inverter, 7404.

Figure 22. Schematic of Avalanche Transistor Impulse Generator. 

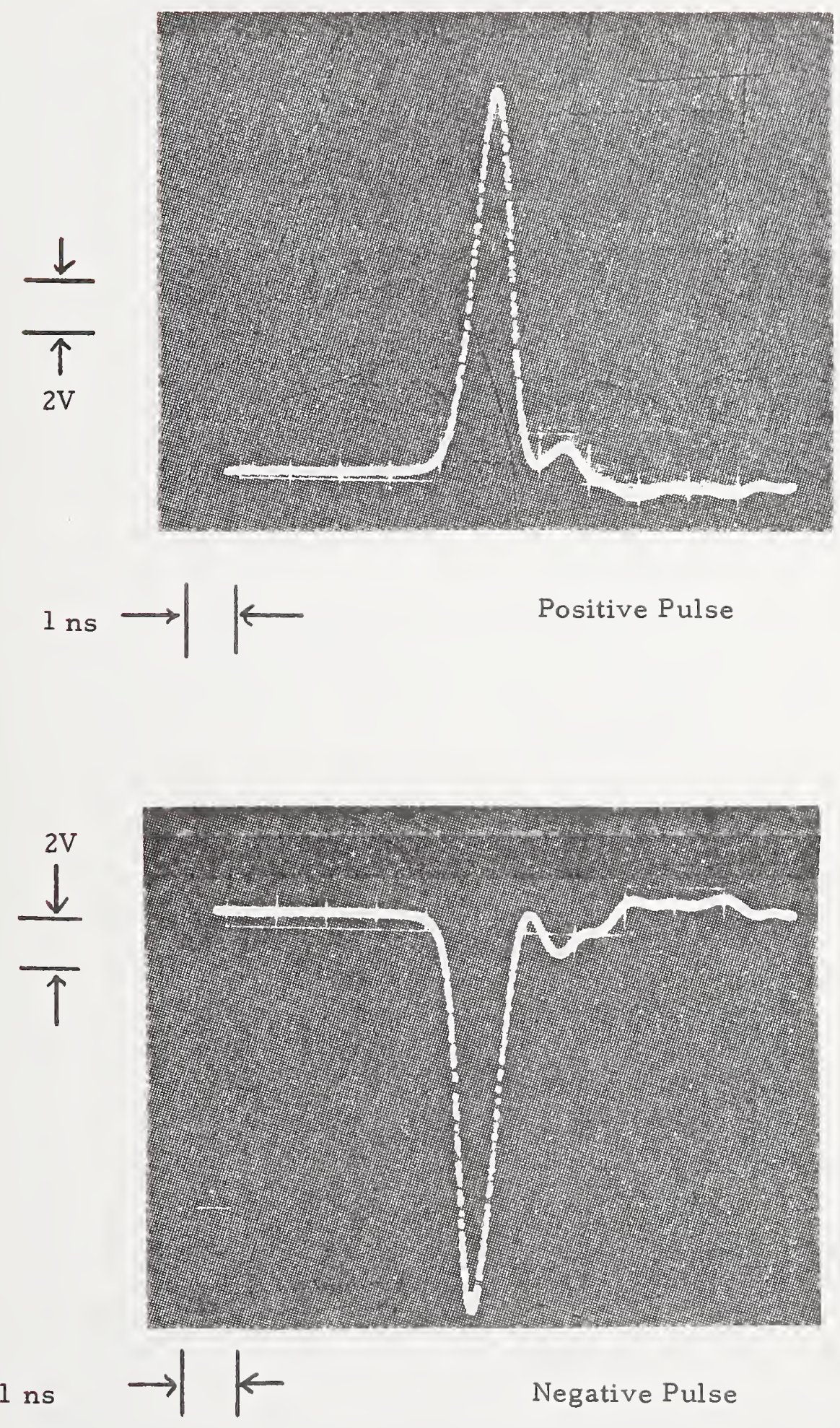

Figure 23. Output of Developmental Solid State Impulse Generator, Wright Patterson AFB. 


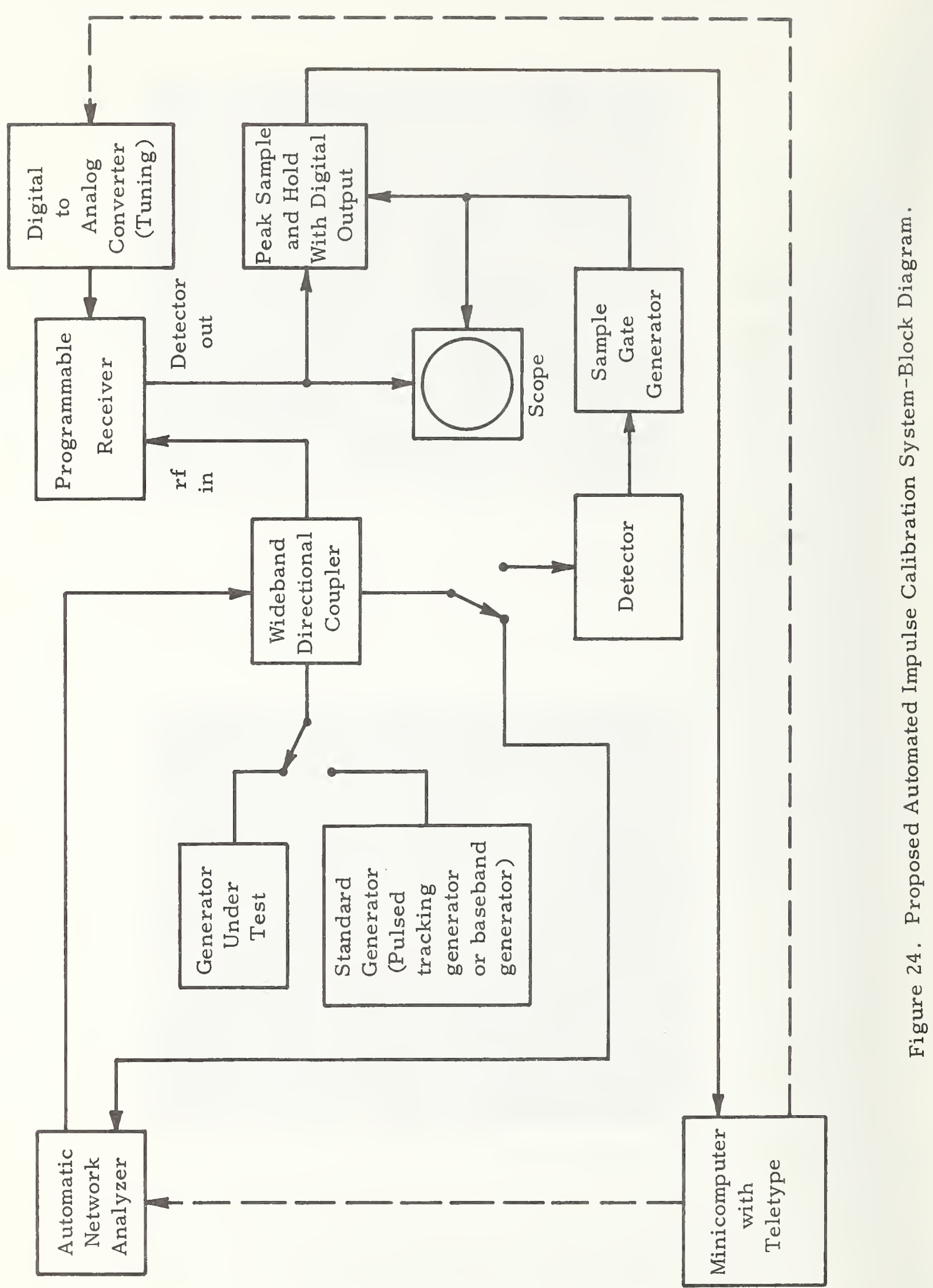




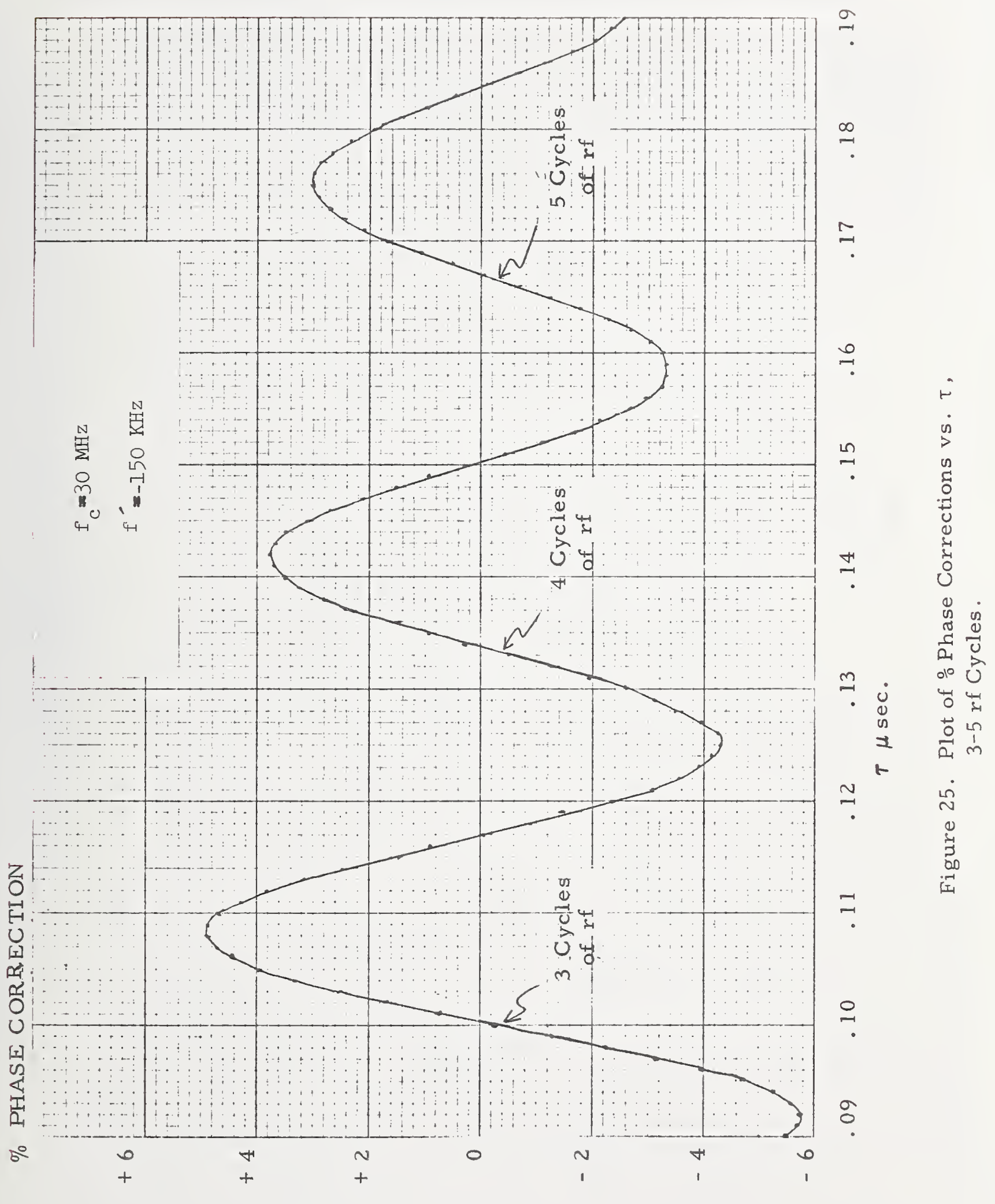




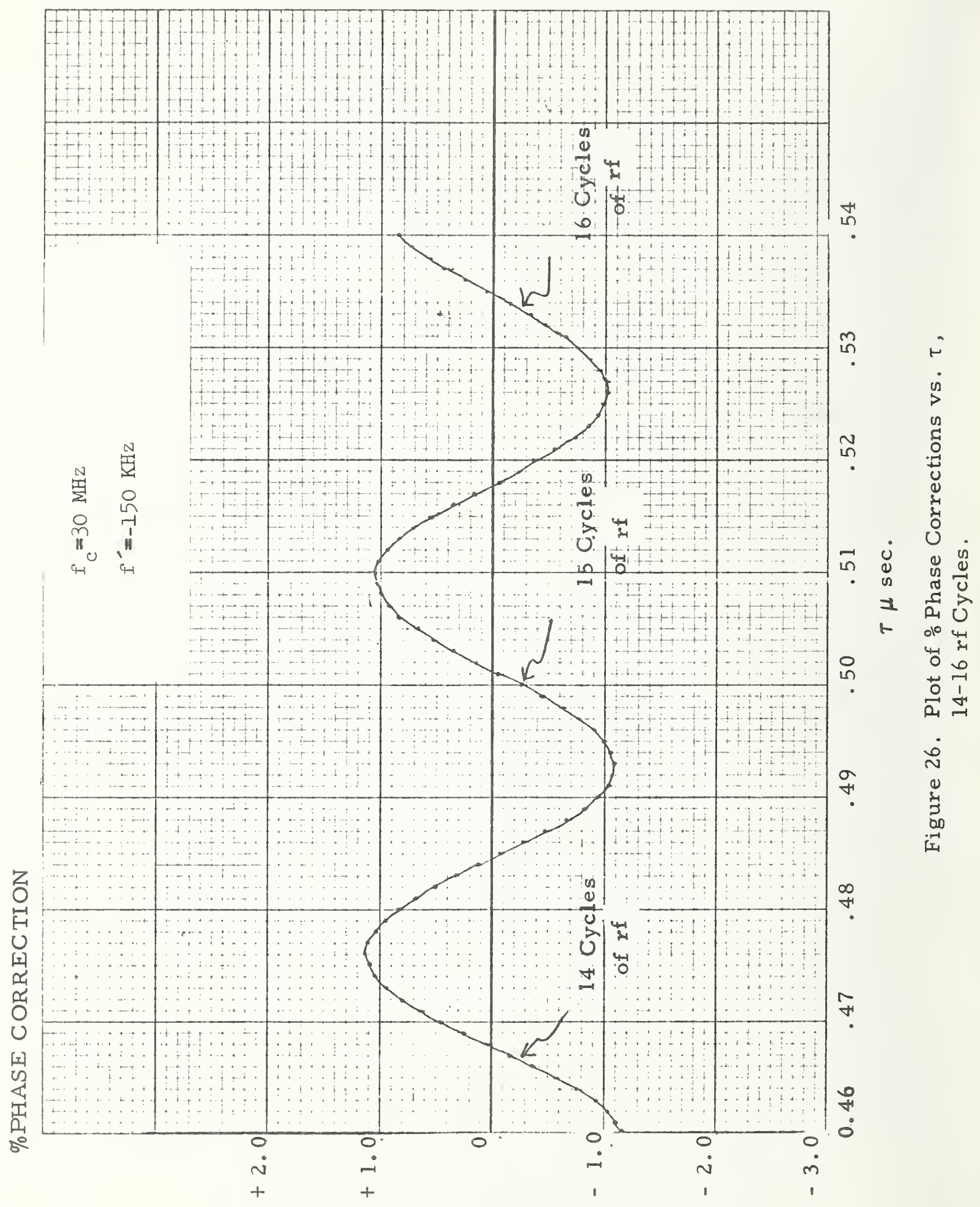


Table I. Difference in Impulse Response at Band Overlap Frequencies, Receiver A.

\begin{tabular}{|c|c|c|}
\hline Bands & Overlap Frequency & Difference (Abs. Value) \\
\hline 1,2 & $30 \mathrm{kHz}$ & $0.7 \mathrm{~dB}$ \\
\hline 2,3 & $60 "$ & $2.8 "$ \\
\hline 3,4 & 120 & $"$ \\
\hline 4,5 & 250 & $1.8^{\prime \prime}$ \\
\hline 5,6 & $500 \quad "$ & $1.0 "$ \\
\hline 6,7 & $1.1 \mathrm{MHz}$ & $0.9 "$ \\
\hline 7,8 & $2.4 \quad 11$ & $2.3 "$ \\
\hline 8,9 & $5 \mathrm{MHz}$ & $3.0 "$ \\
\hline 9,10 & $11 "$ & $1.2 "$ \\
\hline 10,11 & $25 "$ & $3.7 "$ \\
\hline 11,12 & $50 "$ & $1.5 "$ \\
\hline 12,13 & $100 "$ & $2.0 "$ \\
\hline 13,14 & $200 \quad 11$ & $4.8 "$ \\
\hline 14,15 & $500 " 11$ & $4.5 "$ \\
\hline
\end{tabular}


Table II. Performance of $1 \mathrm{GHz}$ Waveguide Beyond Cutoff Attenuator.

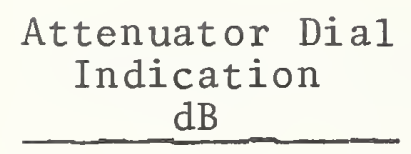

0

1

2

3

4

5
Actual Attenuation $\mathrm{dB}$

0

0.993

1.983

2.969

3.950

4.936
Departure From Linearity $\mathrm{dB}$

0

$+0.016$

$+0.029$

$+0.038$

$+0.042$

$+0.051$

For dial readings greater than $5 \mathrm{~dB}$, the actual attenuation change is determined by multiplying the indicated change by the factor 0.977 .

$$
\mathrm{A}_{\text {actual }}=0.977 \mathrm{~A}_{\text {indicated }}
$$

Al1 measurements were made by setting the dials in the direction of increasing attenuation. The repeatability of the attenuator is estimated to be $\pm 0.001 \mathrm{~dB}$ and the backlash of the dials and gearing is less than $\pm 0.005 \mathrm{~dB}$.

The insertion loss of the attenuator assembly ( 0 dB position) is $43.4 \mathrm{~dB}$. This includes the $6 \mathrm{~dB}$ pad on the output.

The overall accuracy of calibration is $\pm 0.05 \mathrm{~dB}$ out to a setting of $30 \mathrm{~dB}$. 
Table III. Percent Phase Correction for Synchronous Operation.

\begin{tabular}{|c|c|c|c|c|c|c|c|}
\hline \multirow[b]{2}{*}{15} & \multirow[b]{2}{*}{ cycles } & \multicolumn{2}{|c|}{$f^{\prime}$} & $\because$ Correction & \multicolumn{2}{|c|}{$f^{\prime}$} & \multirow{2}{*}{$\begin{array}{l}\text { ¿Correction } \\
-0.250 \\
-0.083 \\
-0.025 \\
-0.008 \\
-0.002\end{array}$} \\
\hline & & $\begin{array}{r}+150 \\
50 \\
15 \\
5 \\
1.5\end{array}$ & $\begin{array}{l}\mathrm{kHz} \\
\mathrm{kHz} \\
\mathrm{kHz} \\
\mathrm{kHz} \\
\mathrm{kHz}\end{array}$ & $\begin{array}{l}0.250 \\
0.083 \\
0.025 \\
0.008 \\
0.003\end{array}$ & $\begin{array}{l}-150 \\
-\quad 50 \\
-\quad 15 \\
-\quad 5 \\
-1.5\end{array}$ & $\begin{array}{l}\mathrm{kHz} \\
\mathrm{kHz} \\
\mathrm{kHz} \\
\mathrm{kHz} \\
\mathrm{kHz}\end{array}$ & \\
\hline 10 & cycles & $\begin{array}{r}+150 \\
50 \\
15 \\
5 \\
1.5\end{array}$ & $\begin{array}{l}\mathrm{kHz} \\
\mathrm{kHz} \\
\mathrm{kHz} \\
\mathrm{kHz} \\
\mathrm{kHz}\end{array}$ & $\begin{array}{l}0.250 \\
0.083 \\
0.025 \\
0.008 \\
0.003\end{array}$ & $\begin{array}{l}-150 \\
-\quad 50 \\
-\quad 15 \\
-\quad 5 \\
-1.5\end{array}$ & $\begin{array}{l}\mathrm{kHz} \\
\mathrm{kHz} \\
\mathrm{kHz} \\
\mathrm{kHz} \\
\mathrm{kHz}\end{array}$ & $\begin{array}{l}-0.250 \\
-0.083 \\
-0.025 \\
-0.008 \\
-0.002\end{array}$ \\
\hline 5 & cycles & $\begin{array}{r}+150 \\
50 \\
15 \\
5 \\
1.5\end{array}$ & $\begin{array}{l}\mathrm{kHz} \\
\mathrm{kHz} \\
\mathrm{kHz} \\
\mathrm{kHz} \\
\mathrm{kHz}\end{array}$ & $\begin{array}{l}0.250 \\
0.083 \\
0.025 \\
0.008 \\
0.003\end{array}$ & $\begin{array}{l}-150 \\
-\quad 50 \\
-\quad 15 \\
-\quad 5 \\
-1.5\end{array}$ & $\begin{array}{l}\mathrm{kHz} \\
\mathrm{kHz} \\
\mathrm{kHz} \\
\mathrm{kHz} \\
\mathrm{kHz}\end{array}$ & $\begin{array}{l}-0.250 \\
-0.083 \\
-0.025 \\
-0.008 \\
-0.002\end{array}$ \\
\hline & & & & $\mathrm{f}_{\mathrm{c}}=10 \mathrm{MHz}$ & & & \\
\hline & cycles & $\begin{array}{r}+150 \\
50 \\
15 \\
5 \\
1.5\end{array}$ & $\begin{array}{l}\mathrm{kHz} \\
\mathrm{kHz} \\
\mathrm{kHz} \\
\mathrm{kHz} \\
\mathrm{kHz}\end{array}$ & $\begin{array}{l}0.745 \\
0.250 \\
0.075 \\
0.025 \\
0.008\end{array}$ & $\begin{array}{l}-150 \\
-\quad 50 \\
-\quad 15 \\
-\quad 5 \\
-1.5\end{array}$ & $\begin{array}{l}\mathrm{kHz} \\
\mathrm{kHz} \\
\mathrm{kHz} \\
\mathrm{kHz} \\
\mathrm{kHz}\end{array}$ & $\begin{array}{l}-0.755 \\
-0.250 \\
-0.075 \\
-0.025 \\
-0.007\end{array}$ \\
\hline 5 & cycles & $\begin{array}{r}+150 \\
50 \\
15 \\
5 \\
1.5\end{array}$ & $\begin{array}{l}\mathrm{kHz} \\
\mathrm{kHz} \\
\mathrm{kHz} \\
\mathrm{kHz} \\
\mathrm{kHz}\end{array}$ & $\begin{array}{l}0.745 \\
0.250 \\
0.075 \\
0.025 \\
0.008\end{array}$ & $\begin{array}{l}-150 \\
-\quad 50 \\
-\quad 15 \\
-\quad 5 \\
-1.5\end{array}$ & $\begin{array}{l}\mathrm{kHz} \\
\mathrm{kHz} \\
\mathrm{kHz} \\
\mathrm{kHz} \\
\mathrm{kHz}\end{array}$ & $\begin{array}{l}-0.755 \\
-0.250 \\
-0.075 \\
-0.025 \\
-0.007\end{array}$ \\
\hline 2 & cycles & $\begin{array}{r}+150 \\
50 \\
15 \\
5 \\
1.5\end{array}$ & $\begin{array}{l}\mathrm{kHz} \\
\mathrm{kHz} \\
\mathrm{kHz} \\
\mathrm{kHz} \\
\mathrm{kHz}\end{array}$ & $\begin{array}{r}+0.745 \\
+0.249 \\
+0.075 \\
0.025 \\
0.008\end{array}$ & $\begin{array}{l}-150 \\
-\quad 50 \\
-\quad 15 \\
-\quad 5 \\
-1.5\end{array}$ & $\begin{array}{l}\mathrm{kHz} \\
\mathrm{kHz} \\
\mathrm{kHz} \\
\mathrm{kHz} \\
\mathrm{kHz}\end{array}$ & $\begin{array}{l}-0.755 \\
-0.250 \\
-0.075 \\
-0.025 \\
-0.007\end{array}$ \\
\hline
\end{tabular}


Table III. Continued

\begin{tabular}{|c|c|c|c|c|c|c|c|}
\hline \multirow[b]{2}{*}{10 cycles } & \multicolumn{2}{|c|}{$f^{\prime}$} & $\%$ Correction & \multicolumn{2}{|c|}{$f^{\prime}$} & \multirow[t]{2}{*}{$\%$} & \multirow{2}{*}{$\begin{array}{l}\text { Correction } \\
-2.564 \\
-0.840 \\
-0.250 \\
-0.083 \\
-0.025\end{array}$} \\
\hline & $\begin{array}{r}+150 \\
50 \\
15 \\
5 \\
1.5\end{array}$ & $\begin{array}{l}\mathrm{kHz} \\
\mathrm{kHz} \\
\mathrm{kHz} \\
\mathrm{kHz} \\
\mathrm{kHz}\end{array}$ & $\begin{array}{l}2.439 \\
0.827 \\
0.250 \\
0.083 \\
0.025\end{array}$ & $\begin{array}{l}-150 \\
-\quad 50 \\
-\quad 15 \\
-\quad 5 \\
-1.5\end{array}$ & $\begin{array}{l}\mathrm{kHz} \\
\mathrm{kHz} \\
\mathrm{kHz} \\
\mathrm{kHz} \\
\mathrm{kHz}\end{array}$ & & \\
\hline 5 cycles & $\begin{array}{r}+150 \\
50 \\
15 \\
5 \\
1.5\end{array}$ & $\begin{array}{l}\mathrm{kHz} \\
\mathrm{kHz} \\
\mathrm{kHz} \\
\mathrm{kHz} \\
\mathrm{kHz}\end{array}$ & $\begin{array}{l}2.439 \\
0.827 \\
0.025 \\
0.083 \\
0.025\end{array}$ & $\begin{array}{l}-150 \\
-\quad 50 \\
-\quad 15 \\
-\quad 5 \\
-1.5\end{array}$ & $\begin{array}{l}\mathrm{kHz} \\
\mathrm{kHz} \\
\mathrm{kHz} \\
\mathrm{kHz} \\
\mathrm{kHz}\end{array}$ & & $\begin{array}{l}-2.546 \\
-0.840 \\
-0.250 \\
-0.083 \\
-0.025\end{array}$ \\
\hline 2 cycles & $\begin{array}{r}+150 \\
50 \\
15 \\
5 \\
1.5\end{array}$ & $\begin{array}{l}\mathrm{kHz} \\
\mathrm{kHz} \\
\mathrm{kHz} \\
\mathrm{kHz} \\
\mathrm{kHz}\end{array}$ & $\begin{array}{l}2.439 \\
0.827 \\
0.250 \\
0.083 \\
0.025\end{array}$ & $\begin{array}{l}-150 \\
-\quad 50 \\
-\quad 15 \\
-\quad 5 \\
-1.5\end{array}$ & $\begin{array}{l}\mathrm{kHz} \\
\mathrm{kHz} \\
\mathrm{kHz} \\
\mathrm{kHz} \\
\mathrm{kHz}\end{array}$ & & $\begin{array}{l}-2.564 \\
-0.840 \\
-0.250 \\
-0.083 \\
-0.025\end{array}$ \\
\hline & & & $\mathrm{f}_{\mathrm{c}}=1 \mathrm{MHz}$ & & & & \\
\hline 10 cycles & $\begin{array}{r}+150 \\
50 \\
15 \\
5 \\
1.5\end{array}$ & $\begin{array}{l}\mathrm{kHz} \\
\mathrm{kHz} \\
\mathrm{kHz} \\
\mathrm{kHz} \\
\mathrm{kHz}\end{array}$ & $\begin{array}{l}6.977 \\
2.439 \\
0.745 \\
0.250 \\
0.075\end{array}$ & $\begin{array}{l}-150 \\
-\quad 50 \\
-\quad 15 \\
-\quad 5 \\
-1.5\end{array}$ & $\begin{array}{l}\mathrm{kHz} \\
\mathrm{kHz} \\
\mathrm{kHz} \\
\mathrm{kHz} \\
\mathrm{kHz}\end{array}$ & & $\begin{array}{l}-8.108 \\
-2.564 \\
-0.755 \\
-0.250 \\
-0.075\end{array}$ \\
\hline 5 cycles & $\begin{array}{r}+150 \\
50 \\
15 \\
5 \\
1.5\end{array}$ & $\begin{array}{l}\mathrm{kHz} \\
\mathrm{kHz} \\
\mathrm{kHz} \\
\mathrm{kHz} \\
\mathrm{kHz}\end{array}$ & $\begin{array}{l}6.977 \\
2.439 \\
0.745 \\
0.250 \\
0.075\end{array}$ & $\begin{array}{l}-150 \\
-\quad 50 \\
-\quad 15 \\
-\quad 5 \\
-1.5\end{array}$ & $\begin{array}{l}\mathrm{kHz} \\
\mathrm{kHz} \\
\mathrm{kHz} \\
\mathrm{kHz} \\
\mathrm{kHz}\end{array}$ & & $\begin{array}{l}-8.109 \\
-2.564 \\
-0.755 \\
-0.250 \\
-0.075\end{array}$ \\
\hline 2 cycles & $\begin{array}{r}+150 \\
50 \\
15 \\
5 \\
1.5\end{array}$ & $\begin{array}{l}\mathrm{kHz} \\
\mathrm{kHz} \\
\mathrm{kHz} \\
\mathrm{kHz} \\
\mathrm{kHz}\end{array}$ & $\begin{array}{l}6.977 \\
2.439 \\
0.745 \\
0.250 \\
0.075\end{array}$ & $\begin{array}{l}-150 \\
-\quad 50 \\
-\quad 15 \\
-\quad 5 \\
-1.5\end{array}$ & $\begin{array}{l}\mathrm{kHz} \\
\mathrm{kHz} \\
\mathrm{kHz} \\
\mathrm{kHz} \\
\mathrm{kHz}\end{array}$ & & $\begin{array}{l}-8.108 \\
-2.564 \\
-0.755 \\
-0.250 \\
-0.075\end{array}$ \\
\hline
\end{tabular}


Table IV. Parameters of Calibration Signals

\begin{tabular}{|c|c|c|c|c|}
\hline $\mathrm{f}_{\mathrm{c}}$ & Pulse Width & Mode & Receiver BW & Max. PRF \\
\hline$>30 \mathrm{MHz}$ & $0.5 \mu \mathrm{sec}$. & asynch. & $300 \mathrm{kHz}$ & $150 \mathrm{kHz}$ \\
\hline $10-30 \mathrm{MHz}$ & $\begin{array}{c}0.1666-0.5 \mu \mathrm{sec} . \\
(5 \mathrm{cycles})\end{array}$ & synch. & $300 \mathrm{kHz}$ & $150 \mathrm{kHz}$ \\
\hline $3-10 \mathrm{MHz}$ & $\begin{array}{c}0.5-1.666 \mu \mathrm{sec} . \\
(5 \mathrm{cycles})\end{array}$ & synch. & $150 \mathrm{kHz}$ & $50 \mathrm{kHz}$ \\
\hline 1-3 $\mathrm{MHz}$ & $\begin{array}{c}1.666-5 \mu \text { sec. } \\
(5 \text { cycles })\end{array}$ & synch. & $30 \mathrm{kHz}$ & $15 \mathrm{kHz}$ \\
\hline$<1 \mathrm{MHz}$ & $\begin{array}{c}0.175 * \mu \text { sec. } \\
\text { (baseband pulse) }\end{array}$ & N.A. & $300 \mathrm{kHz}$ & $150 \mathrm{kHz}$ \\
\hline
\end{tabular}

*5\% rolloff at $1 \mathrm{MHz}$ for which correction is made. 
FORM NBS.114A (1.71)

\begin{tabular}{|c|c|c|c|}
\hline $\begin{array}{l}\text { U.S. DEPT. OF COMM. } \\
\text { BIBLIOGRAPHIC DATA } \\
\text { SHEET }\end{array}$ & $\begin{array}{l}\text { 1. PUBLICATION OR REPORT NO. } \\
\text { NBSIR } 73-343\end{array}$ & $\begin{array}{l}\text { 2. Gov't Accession } \\
\text { No. }\end{array}$ & 3. Recipient's Accession No. \\
\hline \multicolumn{3}{|l|}{ 4. TITLE AND SUBTITLE } & 5. Publication Date \\
\hline \multirow{2}{*}{\multicolumn{3}{|c|}{ Calibration of Impulse Noise Generators }} & October 1973 \\
\hline & & & 6. Performing Organization Code \\
\hline \multicolumn{3}{|l|}{$\begin{array}{l}\text { 7. AUTHOR(S) } \\
\text { Gerome R. Reeve }\end{array}$} & 8. Performing Organization \\
\hline \multicolumn{3}{|c|}{ 9. PERF ORMING ORGANIZATION NAME AND ADDRESS } & $\begin{array}{l}\text { 10. Project/Task/Work Unit No. } \\
2726266\end{array}$ \\
\hline \multicolumn{3}{|c|}{$\begin{array}{l}\text { NATIONAL BUREAU OF STANDARDS, Boulder Labs. } \\
\text { DEPARTMENT OF COMMERCE }\end{array}$} & 11. Contract/Grant No. \\
\hline \multicolumn{3}{|c|}{ Boulder, CO 80302} & $\begin{array}{l}\text { U.S. Army Contract } \\
67-95896\end{array}$ \\
\hline \multicolumn{3}{|c|}{$\begin{array}{l}\text { 12. Sponsoring Organization Name and Address } \\
\text { U.S. Army Electronics Command } \\
\text { AMSEL-NL-C } \\
\text { Fort Monmouth, New Jersey }\end{array}$} & $\begin{array}{l}\text { 13. Type of Report \& Period } \\
\text { Covered Final Report } \\
\text { Find } \\
\text { Dec.1966 - June } 1972 \\
\text { 14. Sponsoring Agency Code }\end{array}$ \\
\hline
\end{tabular}

15. SUP PLEMENTARY NOTES

16. ABSTRACT (A 200-word or less factual summary of most significant information. If document includes a significant bibliography or literature survey, mention it here.)

This report covers work performed by the Electromagnetics Division, Institute for Basic Standards, National Bureau of Standards, on a Signal Corps contract to develop a calibration system for impulse noise generators. Various technical approaches are discussed with their respective problems. A prototype system which was constructed is presented along with some measurements of its capability. Finally another approach is suggested utilizing newer techniques and instrumentation which should come closer to achieving the desired level of performance.

17. KEY WORDS (Alphabetical order, separated by semicolons)

Impulse; impulse generator calibration; impulse noise; impulse noise generator.

18. AVAILABILITY STATEMENT

\section{UNLIMITED.}

FOR OFFICIAL DISTRIBUTION. DO NOT RELEASE TO NTIS.

\begin{tabular}{|l|l|}
$\begin{array}{l}\text { 19. SECURITY CLASS } \\
\text { (THIS REPORT) }\end{array}$ & 21. NO. OF P AGES \\
UNCL ASSIFIED & 22. Price \\
\hline $\begin{array}{l}\text { 20. SECUR ITY CLASS } \\
\text { (THIS PAGE) } \\
\text { UNCL ASSIFIED }\end{array}$ & \\
\hline
\end{tabular}



